\title{
Entry, Descent, and Landing with Propulsive Deceleration: Supersonic Retropropulsion Wind Tunnel Testing and Shock Phenomena
}

\author{
Bryan Palaszewski* \\ NASA John H. Glenn Research Center \\ Lewis Field \\ MS 5-10 \\ Cleveland, $\mathrm{OH} 44135$ \\ (216) 977-7493 Voice* \\ (216) 433-5802 FAX* \\ bryan.a.palaszewski@nasa.gov
}

Fuels and Space Propellants Web Site:

http://www.grc.nasa.gov/WWW/Fuels-And-Space-Propellants/foctopsb.htm

The future exploration of the Solar System will require innovations in transportation and the use of entry, descent, and landing (EDL) systems at many planetary landing sites. The cost of space missions has always been prohibitive, and using the natural planetary and planet's moon atmospheres for entry, and descent can reduce the cost, mass, and complexity of these missions. This paper will describe some of the EDL ideas for planetary entry and survey the overall technologies for EDL that may be attractive for future Solar System missions. Future EDL systems may include an inflatable decelerator for the initial atmospheric entry and an additional supersonic retro-propulsion (SRP) rocket system for the final soft landing.

A three engine retro-propulsion configuration with a 2.5 inch diameter sphere-cone aeroshell model was tested in the NASA Glenn 1x1 Supersonic Wind Tunnel (SWT). The testing was conducted to identify potential blockage issues in the tunnel, and visualize the rocket flow and shock interactions during supersonic and hypersonic entry conditions. Earlier experimental testing of a 70 degree Viking-like (sphere-cone) aeroshell was conducted as a baseline for testing of a supersonic retro-propulsion system. This baseline testing defined the flow field around the aeroshell and from this comparative baseline data, retro-propulsion options will be assessed. Images and analyses from the SWT testing with 300- and 500-psia rocket engine chamber pressures are presented here. In addition, special topics of electromagnetic interference with retro-propulsion induced shock waves and retro-propulsion for Earth launched booster recovery are also addressed.

\section{Introduction}

Entry, descent, and landing are a series of events needed to safely land on the surface of another body in the solar system which possesses an atmosphere. Thusly, Mars, Venus, the outer planets, and the outer planet moon, Titan, all require technologies that will protect the spacecraft from the high temperatures created during the initial hypersonic entry, and finally slow the vehicle from that hypersonic speed into the supersonic regime, then to subsonic and of course the final touchdown. In the outer planet atmospheres, the final landing would be replaced with a buoyancy system such as an airship or balloon, or an aircraft.

\section{Historical Missions}

Landing space vehicles on other planetary bodies is a challenge in propulsion, precision, control, and guidance. As there is no atmosphere surrounding Earth's Moon, the lunar landings of robotic Surveyor and human Apollo missions used propulsion for the entire descent. The same was true for the successful Luna and Lunakhod flights of the U.S.S.R. For Venus with its dense atmosphere, landing vehicles used aeroshell and parachute combinations, with crushable elements (balsa wood, etc) to absorb the final landing energy. On Mars, the landing vehicles became more massive and complex (Viking, Pathfinder, Mars Exploration Rovers (MER), Mars Science Laboratory (MSL)), and the since the atmosphere was very thin, the final landing systems was a combination for aeroshell, parachute and retro rockets. To allow landing in more rugged areas of Mars, an additional airbag system was devised for the Pathfinder and MER landers to assure a successful landing in rock strewn sites.

\footnotetext{
* Leader of Advanced Fuels, AIAA Associate Fellow
} 


\section{Mars}

Several EDL configurations are under assessment for Mars. Figure 1 presents the historical comparison of the USA Mars entry capsules (Ref. 1). The typical 70 degree cone angle for these configurations was selected for high stability and high drag. As the planet's atmosphere is quite thin, the blunt body can provide the needed drag for relatively small payloads of up 1 metric ton. As the mass of the lander vehicle increases, a different set of EDL technologies are required. Based on past studies (Refs. 2 and 3), parachutes are impractical for vehicles with lander masses of over 20 metric tons. The lander's parachutes would be too big to deploy effectively and reliably. Therefore a combination of inflatable decelerators (for hypersonic and supersonic speeds) and supersonic retro-propulsion has been suggested. Many past studies have investigated landing on Mars with aerodynamic systems (Ref. 5 to 8). However, the most recent studies imply that the past studies assumptions are too optimistic and are in need of revision to assure success. Supersonic retro propulsion, perhaps beginning as early as Mach 5, will therefore likely be required for soft landing on Mars.

\section{Experimental Planning}

While the Viking-like aeroshell design has proven successful for missions, but higher mass missions of many tens of tons will likely require more energetic retro-propulsion. Figures 2 and 3 show some of the historical testing on supersonic retro-propulsion (Ref. 3). This testing was only pursued with relatively small models and did not result in flight test hardware. To expand the relatively small data base of supersonic retro-propulsion information, a series of test programs were established and planned. The NASA Glenn Research Center's 1 foot $x 1$ foot (1x1) Supersonic Wind Tunnel (SWT) was used for the testing. It has a wide range of test velocities from Mach 2.0 to 6.0. Several types of data were gathered during the testing: surface pressure measurements, surface temperature measurements, and low speed and high speed digital Schlieren video movie imaging.

Model development began for a 2.5-inch diameter aeroshell. The 2.5-inch size was selected based on the previous wind tunnel testing of the aerodynamic blockage of the tunnel. The initial model was based on the 70 degree sphere-cone shape of the Viking entry capsule. It was attached to a sting-strut that was adjustable and can hold the model at a flexible angle of attack from 0 to 20 degrees of angle of attack (AoA). The construction of the model and sting strut was stainless steel. The model was also instrumented with both temperature sensors and pressure transducers. There were 3 thermocouples and 9 pressure ports on the windward side of aeroshell. There were three thermocouples and three pressure ports on leeward side of aeroshell. One additional thermocouple was placed near the trailing edge of the strut. High frequency pressure transducers (kulites) were used to measure the engine chamber pressures and tunnel wall pressures in three locations. Optical access to the test section allowed imaging with low speed and high speed Schlieren video movie recording. The high speed Schlieren recordings were made at 500 frames per second.

\section{Test Data}

Testing commenced on March 17, 2010 for a 1 day period. The tunnel operations were very smooth and in each test run, the tunnel pressure increased until the flow was started on the model and a stable bow shock was established. The tunnel pressure was then adjusted until the minimum pressure for tunnel operation was reached. Data was taken at this point, and then successive data points were taken at the remaining Mach Numbers. Measurements were taken at Mach = 2.5, 3.0, 3.5, 4.0, and 5.0. Trailerprovided air was used for the simulated rocket engine flow. The rocket nozzle design was derived from Ref. 4.

During the testing, it was noted that with the 2.5-inch model, an initial stable bow shock could be established at all Mach Numbers. Based on previous testing, no unanticipated aerodynamic blockage occurred when the engines were not firing. When the rocket engines were firing, significant tunnel unstarts occurred in only several runs, and their occurrences are noted in Table I. The tunnel unstarts occurred with all of the 500 psia runs at $\mathrm{M}=2.5$ and 3.0 and with all of the 300 psia runs at $\mathrm{M}=2.5$. At all other conditions, excellent model performance was demonstrated with minimal wall interactions.

Figure 4 shows a typical Schlieren image for the baseline SWT testing 3 retro-propulsion engines. The Mach Number was 2.91 $(\mathrm{M}=3.0$ range). The angle of attack was 0 degrees. Note that at $\mathrm{M}=3.0$, the bow shock has a small interaction with the tunnel walls in the image. Additional data was gathered at Mach Number $=3.5,4.0$, and 5.0, with the angle of attack at 0.0 degrees, and these results are shown in Figure 4, 5, 6, and 7, respectively. As the Mach number increases, there is less noticeable or no wall shock interaction in the images. On most runs, we are searching and striving to reach the lowest Reynolds Number / foot and the lowest total pressure at each Mach Number, so that we can more accurately simulate the Mars entry conditions. Higher values of Reynolds Number / foot can represent other atmospheric entries into Earth, the outer planets, and Titan.

The location of the bow shock very close to the sphere-cone model was unforeseen. The rocket engines in past testing have used higher engine pressures of up to $1500 \mathrm{psia}$, and thus the bow shock is often far from the body, perhaps one to several entry vehicle diameters. The lower pressures used here were seen to penetrate the bow shock and that shock remained very near the entry body model. Such shock locations will have likely significant influence on vehicle heating due to shock impingement, etc. 
An important parameter for the retro-propulsion testing is the thrust coefficient. It is the ratio of the thrust of the vehicle to the drag of the vehicle and is computed with this equation (Ref. 3):

$$
C_{T}=\frac{2}{\gamma_{\infty} M_{\infty}^{2}} \cdot \frac{P e}{P_{\infty}} \frac{A e}{A_{B}}\left(1+\gamma_{e}{ }_{e}{ }^{2}\right)
$$

Where:

$\mathrm{C}_{\mathrm{T}}$

Gamma, infinity

M, infinity

$\mathrm{P}_{\mathrm{e}}$

$P$, infinity

$\mathrm{A}_{\mathrm{e}}$

$\mathrm{A}_{\mathrm{B}}$

Gamma, exit

$\mathrm{M}_{\mathrm{e}}$
Thrust coefficient

Ratio of specific heats at infinity

Mach Number at infinity

Pressure at nozzle exit

Pressure at infinity (tunnel pressure)

Nozzle exit area

Test article projected area

Ratio of specific heats at nozzle exit

Mach Number at nozzle exit

Figure 8 illustrates the thrust coefficient versus Mach Number for four engine chamber pressures: 200, 300, 500, and 1500 psia. The engine expansion ratio is $10: 1$. For the test cases below $500 \mathrm{psia}$, the thrust coefficient is a maximum of 0.36 , Only when the chamber pressure is near $1500 \mathrm{psia}$ and near $\mathrm{M}=2.0$ will the thrust coefficient be equal to or greater than 1.0. Computations of the thrust coefficients at other planned expansion ratios (4:1,20:1, and 50:1) show very similar results.

Testing with retro-rocket configurations was planned to include flexible changes of the nozzle expansion ratio and the angle of attack. The overall design of a retro-propulsion model is shown in Figures 9, 10, and 11. Three expansion rations of 10:1, 20:1 and 4:1 are shown, respectively. Appendices A1, A2, ands A3 show the Schlieren images from the runs with a chamber pressure of 300 and 500 psia, at an angle of attack of $0.0,10.0$ and 15.0 degrees. Again, over the entire test program, rocket engine chamber pressures of 200,300 and 500 psia were tested with the 10:1 rocket engine expansion ratio. Appendix B provides the test conditions for each run: tunnel total and static pressures, and the tunnel Reynolds Number/foot. Appendix C provides a detailed drawing of the windward side of the aeroshell test model.

\section{Thoughts on Alternate Retro-Propulsion Configurations}

Figure 12 shows the Mars Lander configuration of the Design Reference Architecture 5 (DRA-5, Ref. 9). As currently designed, the vehicle has a large series of open trusses that support the subsystems of the vehicle: tankage, propellants, engines, rover(s), return vehicle, etc. During EDL, it has been suggested that the aeroshell surrounding the vehicle can be released at supersonic speed and the main engines be used for supersonic retro-propulsion. With all of the major open trusses of the lander structure in the aerodynamics stream, this would lead to severe damage to the lander (and is not recommended). By using a combination of deployable structures and supersonic retro-propulsion, the vehicle could be much more controllable and safe from unwanted aerodynamic heating.

Saturn I retrorocket separation - The Saturn I rocket from the 1960s used a retrorocket system to assist with the first and second stage separation. The separation motors were solid rockets, and were used to assure that the stages did not collide during separation. The retro rocket flow field was analyzed (see Figures 13 and 14)and predictions made of the influence of the flow field on vehicle communications (Ref. 10). Such analyses will likely be important in future Mars exploration missions using supersonic retro-propulsion.

USAF RBS Rocketback maneuver - The USAF reusable booster system (RBS) has been suggested as a potential new launch vehicle (Ref 11 and 12). The RBS is composed on a reusable rocket powered first stage and a rocket powered second stage, as shown in Figure 15. In the suggested design, the booster staging separation velocity is so high that the first stage must employ a 
rocket back maneuver (see Figure 15). After staging, the first stage vehicle will turn to fire its main engines into the oncoming airflow, and slow the vehicle down so that it may return to the launch site. Figure 16 shows a flowfield calculation for 4 angles of attack (Ref. 12). Severe heating may be experienced during this maneuver.

Fins - Due to the severity and large variations of the flow field from the retro rockets, extensions from the entry body may be an important option for stability enhancements. Past testing at supersonic speed of fin extensions (grid fins, etc.) shows that such configurations can provide the stability enhancements for missiles and human rated vehicles (Russian Soyuz launch vehicle, etc.). The 4 grid fins are mounted on the sides of the vehicles and provide enhanced stability during the use of the launch escape system. U.S. Army and international missile testing (Refs. 13 to 21) has also evaluated grid fins. The missile testing was for long slender missiles, and hence the application may be for a more restricted set of higher lift to drag (L/D) EDL configurations (biconic aeroshells, etc.

\section{Concluding Remarks}

Experimental programs were planned and executed to gather data of supersonic propulsive deceleration (or supersonic retropropulsion). Initial data gathering was successful and this data will be used as the comparative baseline for upcoming larger scale retro-propulsion testing. Schlieren imaging was captured to assess the successful formation of the bow shock surrounding the aeroshell. In some cases, the shock interactions with the SWT walls occurred and were also visualized. The high speed camera video at 500 frames per second identified the chaotic nature of the retro-rocket - shock interactions. More detailed data and image analyses are continuing. Test planning and model development has been conducted for additional retro-rocket equipped aeroshells with different area ratio rocket nozzles: 4:1, 20:1, and 50:1. Due to test time limitations, the 4:1, 20:1, and 50:1 expansion ratios were not tested.

Entry, descent, and landing technologies are under development for the high mass Mars Entry system (HMMES). Many investigations of aerodynamic deceleration for the outer planets have been conducted as well. The challenges for EDL are numerous, especially for inflatable decelerator and the interactions that will occur with propulsive deceleration retro propulsion. The high velocities involved in entry and descent will require high temperature materials that are flexible for folding into a small volume, but reliable when they are deployed to their full diameter.

Many exciting possibilities are foreseen for Mars and outer planet exploration and exploitation (Refs. 23 to 39). The resources of the outer planets may allow fueling of nuclear fusion vehicles and other power plants that may be the engine for all of Earth's energy. Wresting fuels such as hydrogen and helium 3 from the gas giant planets may be a critical element of outer planet exploration and also flight to the nearby stars. The EDL systems will be an integral part of all of these exploration and exploitation scenarios.

\section{Acknowledgements}

We would like to thank Bob McCluskey (NASA), Steve Pesek (Jacobs Sverdrup, JSV), Barry Piendl (JSV), and Scott Smrdel (also of JSV). The team also included the test hardware design expertise of Jim Buckley (Arctic Slope Research Corporation, ASRC) and David Root (also of ASRC).

\section{References}

Entry, Descent, and Landing:

1) Karl T. Edquist, Artem A. Dyakonov, Michael J. Wright, and Chun Y. Tang, "Aerothermodynamic Environments Definition for the Mars Science Laboratory Entry Capsule," AIAA 2007-1206, 45th AIAA Aerospace Sciences Meeting and Exhibit, Reno, Nevada, 8 - 11 January 2007.

2) Karl T. Edquist and Stephen J. Alter, "Computational Aeroheating Predictions for Mars Lander Configurations," AIAA 20033639, 36th AIAA Thermophysics Conference, Orlando, Florida, 23-26 June 2003.

3) Philip O. Jarvinen and Richard H. Adams, "The Aerodynamic Characteristics of Large Angled Cones with Retrorockets: Final Report,” Contract No. NAS 7-576, Prepared by MITHRAS, Report number MC 70 - 3001 - R2 (BNY), February 1970.

4) Putnam, L. and Capone, F., "Experimental Determination of Equivalent Solid Bodies to Represent Jets Exhausting into a Mach 2.20 External Stream,” NASA TN-D-5553, December 1969.

Mars:

5) Palaszewski, B., Frisbee, R., “Advanced Propulsion for the Mars Rover Sample Return Mission,” AIAA PAPER 88-2900, Jul 01, 1988. 
6) Hepp, Aloysius F., Linne, Diane L., Landis, Geoffrey A. Inc.,, Groth, Mary F. Colvin, James E., "Production and Use of Metals and Oxygen for Lunar Propulsion,” NASA-TM-105195, AIAA PAPER 91-3481, Jan 01, 1991.

7) Linne, Diane L., and Meyer, Michael L., "Technical prospects for utilizing extraterrestrial propellants for space exploration," NASA-TM-105263 presented at the 42nd International Astronautical Congress, Montreal, Quebec, 5-11 Oct. 1991; sponsored by International Astronautical Federation International Astronautical Congress Montreal, Quebec, 5-11 Oct. 1991.

8) Rice, E., "Final Report On Advanced System Concept For Total ISRU Based Propulsion And Power Systems For Unmanned And Manned Mars Exploration" Orbital Technologies Corporation, National Institute for Advanced Concepts (NIAC) Phase II Contract, Research Grant 07600-041, OTC-GS-0096-FR-2002-1, Universities Space Research Association (USRA), 30 April 2002. Also, see: http://www.niac.usra.edu/files/studies/final_report/pdf/395Rice.pdf

9) Drake, Bret (editor), “Human Exploration of Mars Design Reference Architecture 5.0.” NASA SP-2009-566, July 2009.

Alternate Retro-Propulsion Configurations and Vehicle Stability Options:

10) Jacobs, D. B., "Development of Saturn 5 radio flame effects prediction Final Report ," The Boeing Company, NASA-CR105833, D5-15606-1, Contract/ NAS8-5608, Feb 27, 1967

10) Anon., "NASA KSC/AFRL Reusable Booster System (RBS) Concept of Operations (ConOps)," RBS ConOps Study Team Kennedy Space Center, FL, December 7,2010.

11) Barry M. Hellman, Dr. Scott E. Sherer, Christopher R. Schrock, Brock J. Pleiman, Anthony J. Piplic, and Dr. Brad St. Germain "Critical Flight Conditions of Operational Rocketback Trajectories," AIAA SPACE 2012 Conference \& Exposition, AIAA 2012-5208, September 2012.

12) James DeSpirito, Harris L. Edge, Paul Weinacht, Jubaraj Sahu, and Surya Dinavahi, “Computational Fluid Dynamic (CFD) Analysis of a Generic Missile With Grid Fins," ARL-TR-2318, September 2000.

13) K. Mohamed Bak, "EXPERIMENTAL INVESTIGATION AND COMPUTATIONAL FLUID DYNAMICS ANALYSIS OF MISSILE WITH GRID FIN IN SUBSONIC FLOW,” International Journal of Engineering Science and Technology, Vol. 2(11), 2010, 6214-6220.

14) Philippe Reynier, Uwe Reisch, José-Maria Longo, Rolf Radespiel, "Flow predictions around a missile with lattice wings using the actuator disc concept," Aerospace Science and Technology, Volume 8, Issue 5, July 2004, Pages $377-388$.

15) Despirito, J., Vaughn, M., Washington, W.D. "CFD investigation of canard controlled missile with planar and grid fins in supersonic flow," AIAA Paper 2002-4509, August 2002.

16) Gregg Abate, Gerald Winchenbach, and Wayne Hathaway, "Transonic Aerodynamic and Scaling Issues for Lattice Fin Projectiles tested in a Ballistics Range,” 19th International Symposium of Ballistics, 7-11 May 2001, Interlaken, Switzerland.

17) James Despirito, Harris L.Edge, Paul Weinacht and Juburaj Sahu. "CFD Analysis of Grid for Maneuvering Missiles” AIAA 2000-0391.

18) E.Y. Fournier, "Wind tunnel investigation of a high L/D projectile with grid fin and conventional planar control surfaces". 19 th International Symposium of Ballistics, 7-11 May 2001, Interlaken, Switzerland.

19) John E. Burkhalter, Roy J. Hartfield, and Todd M.Leleux "Nonlinear Aerodynamic Analysis of Grid Fin Configurations" Journal of Aircraft Vol.32 No.3, May - June 1995.

20) Ross A. Brooks and John E. Burk halter "Experimental and Analytical Analysis of Grid Fin Configurations" Journal of Aircraft Vol.26 No.9, September1989.

21) John E. Burkhalter and Harris M. Frank "Grid Fin Aerodynamics for Missile Applications in Subsonic Flow," Journal of Spacecraft and Rockets. Vol. 33, No.1 Jan - Feb 1996.

22) Andrews, Dana, “Design Optimization of High Mass Mars Entry Systems,” Paper Number IAC-08.D2.3.8 Andrews Space \& Technology, 2008. 
The Outer Planets:

23) Powell, Paniagua, Maise, Ludewig, Todosow Exploration of Jovian Atmosphere Using Nuclear Ramjet Flyer, IAF 98-S.6.08, PUR-4, 24 July '98. Also, see: http://www.newworlds.com/reports/PUR-4.PDF

24) John Paniagua, James R. Powell and George Maise, "Europa Sample Return Mission Utilizing High Specific Impulse Propulsion Refueled with Indigenous Resources," Report No. PUR. 21, PHASE I. FINAL REPORT, Plus Ultra Technologies, Inc., National Institute for Advanced Concepts (NIAC) Phase I Grant 07600-077, Prime Contract Number NAS5-98051, November 30, 2001. Also see: http://www.niac.usra.edu/files/studies/final_report/pdf/638Paniagua.pdf

25) V.I. Shematovich and R.E. Johnson, "NEAR-SURFACE OXYGEN ATMOSPHERE AT EUROPA,” Adv. Space Res. Vol. 27, No. 11, pp. 1881-1888, 2001, Pergamon Press, (C) 2001 COSPAR. Published by Elsevier Science Ltd., Printed in Great Britain.

26) Christopher F. Chyba* and Cynthia B. Phillips, "Possible ecosystems and the search for life on Europa," PERSPECTIVE, Proceedings of the National Academy of Sciences (PNAS), USA, January 30, 2001 u vol. 98,no. 3, pp. 801-804.

27) Thomas B. McCord, Gary B. Hansen, and Charles A. Hibbitts, "Hydrated Salt Minerals on Ganymede's Surface: Evidence of an Ocean Below," Science, 2001 May 25; 292: 1523-1525.

28) T. B. McCord, R. W. Carlson, W. D. Smythe, G. B. Hansen, R. N. Clark, C. A. Hibbitts, F. P. Fanale, J. C. Granahan, M. Segura, D. L. Matson, T. V. Johnson, and P. D. Martin, "Organics and Other Molecules in the Surfaces of Callisto and Ganymede," Science, 1997 October 10; 278: 271-275.

29) Adam P. Showman and and Renu Malhotra, “The Galilean Satellites,” Science 1999 October 1; 286: 77-84.

30) R. Carlson, W. Smythe, K. Baines, E. Barbinis, K. Becker, R. Burns, S. Calcutt, W. Calvin, R. Clark, G. Danielson, A. Davies, P. Drossart, T. Encrenaz, F. Fanale, J. Granahan, G. Hansen, P. Herrera, C. Hibbitts, J. Hui, P. Irwin, T. Johnson, L. Kamp, H. Kieffer, F. Leader, E. Lellouch, R. Lopes-Gautier, D. Matson, T. McCord, R. Mehlman, A. Ocampo, G. Orton, M. Roos-Serote, M. Segura, J. Shirley, L. Soderblom, A. Stevenson, F. Taylor, J. Torson, A. Weir, and P. Weissman, "Near-Infrared Spectroscopy and Spectral Mapping of Jupiter and the Galilean Satellites: Results from Galileo's Initial Orbit," Science, 1996 October 18; 274 : 385-388.

31) R. W. Carlson, M. S. Anderson, R. E. Johnson, W. D. Smythe, A. R. Hendrix, C. A. Barth, L. A. Soderblom, G. B. Hansen, T. B. McCord, J. B. Dalton, R. N. Clark, J. H. Shirley, A. C. Ocampo, and D. L. Matson, "Hydrogen Peroxide on the Surface of Europa," Science 1999 March 26; 283: 2062-2064.

32) Amanda E. Lowell, Kah-Siew Ho, and Robert A. Lodder, "Remote Hyperspectral Imaging of Endolithic Biofilms Using a Robotic Probe," Contact in Context:vli1/planetprobe, Copyright 2002 Contact in Context. This article is available at http://cic.setileague.org/v1i1/planetprobe.pdf

33) Frank D. Carsey, Gun-Shing Chen, James Cutts, Lloyd French, Roger Kern, A., Lonne Lane, Paul Stolorz, and Wayne Zimmerman, and Phil Ballou Exploring Europa's Ocean: A Challenge For Marine Technology Of This Century," JPL 00-0221, Marine Technology Society Journal, Deep Ocean Frontiers Issue, Washington D.C., USA, 2000.

http://techreports.jpl.nasa.gov/2000/00-0221.pdf

34) David F. Woerner, "Revolutionary Systems And Technologies For Missions To The Outer Planets," Advanced Scientific Space Missions, Aosta, Italy, June 29-July 1, 1998. http://techreports.jpl.nasa.gov/1998/98-0522.pdf

35) Palaszewski, B., "Atmospheric Mining in the Outer Solar System: Mission Scenarios and Options For In-Situ Resource Utilization,” AIAA 2007-5598, July 2007.

36) Palaszewski, B., “Atmospheric Mining in the Outer Solar System: Vehicle Design Issues,” AIAA 2006-5222, July 2006.

37) Palaszewski, B., “Atmospheric Mining in the Outer Solar System,” AIAA 2005-4319, July 2005.

38) Andrews, D. G. (Boeing Co., Seattle, Wash.) Bloetscher, F. (Goodyear Aerospace Corp., Akron, Ohio), “Aerobraked Orbital Transfer Vehicle Definition,” AIAA-1981-279, January 1981, 9 p.

39) R. Dyke, Swales Aerospace, Hampton, VA, and G. Hrinda, NASA Langley Research Center, Hampton, VA, " Structural Design For A Neptune Aerocapture Mission,” AIAA-2004-5179, August, 2004. 


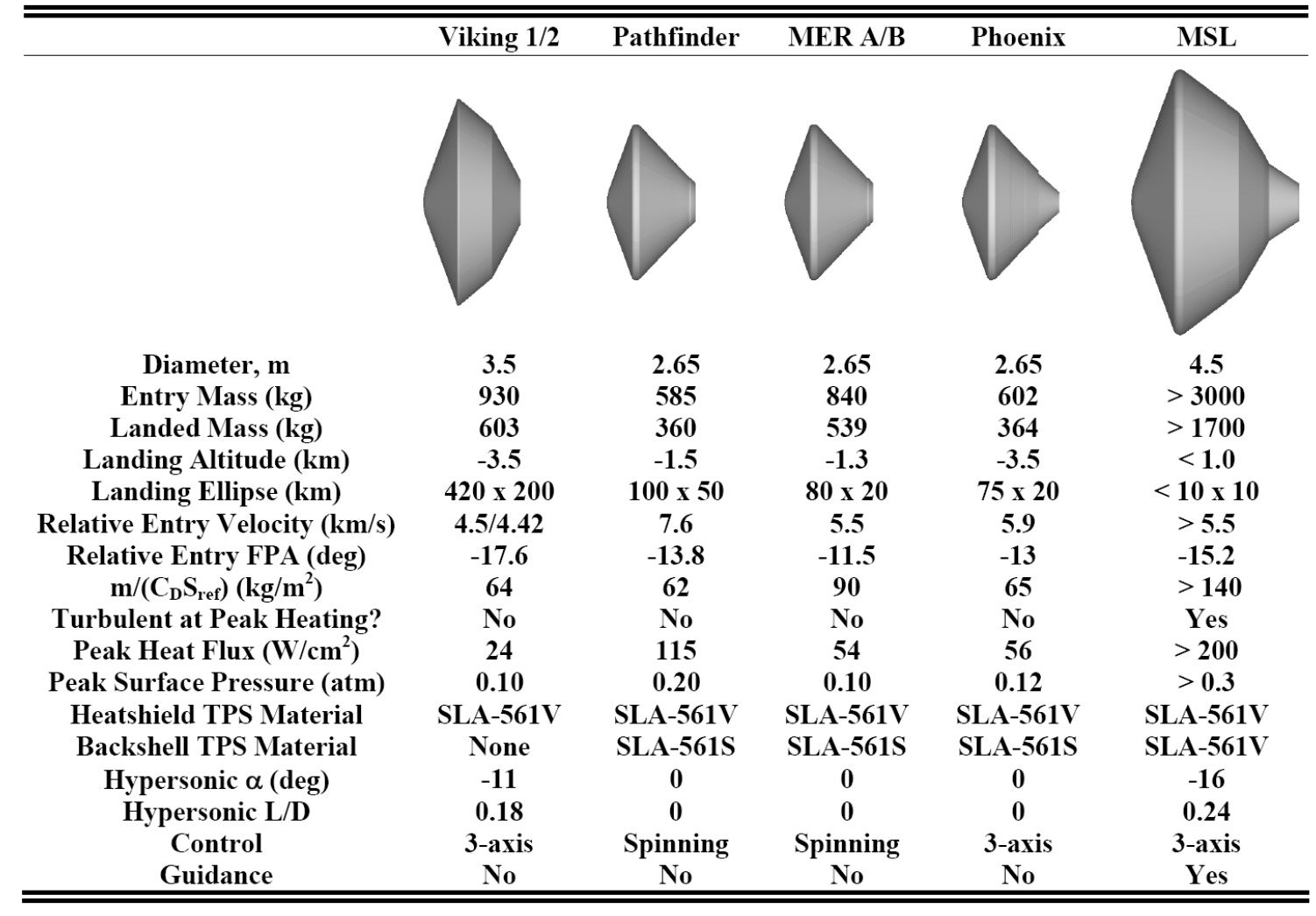

Figure 1. Comparison of Viking-spacecraft-like (sphere-cone) aeroshells for Mars entry (Ref. 1).
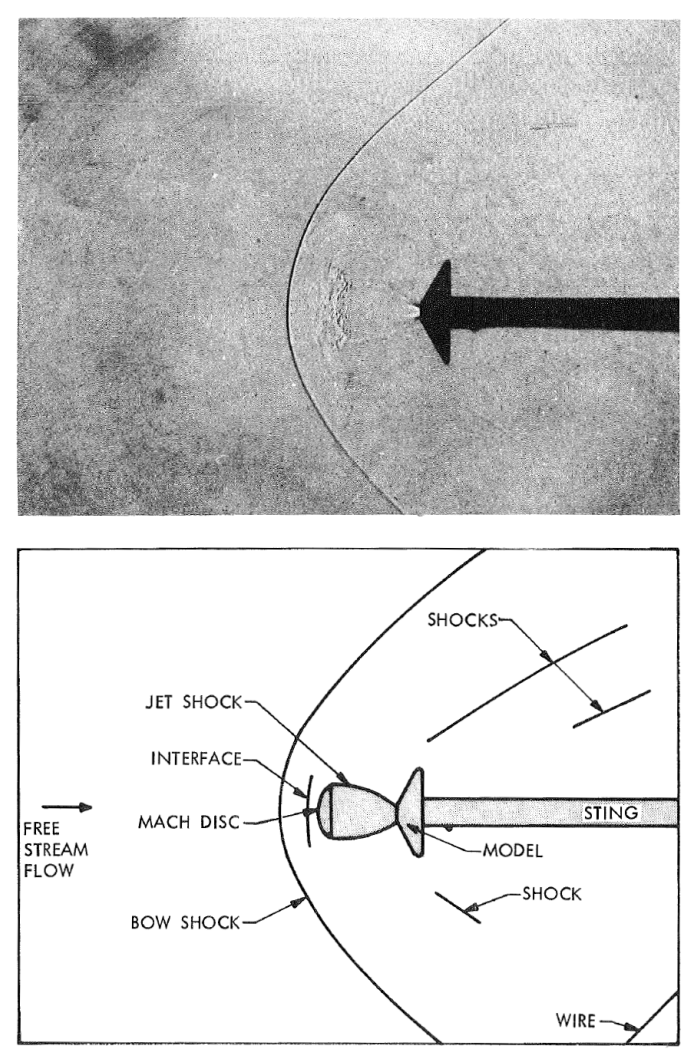

Figure 14 Single Nozzle $60^{\circ}$ Aeroshell Model with Blunt Flow Interaction,
\[ M_{\infty}=2.0, C_{T}=1.1 . \]

Figure 2. Historical retro-propulsion testing (Ref. 3, 1970). 


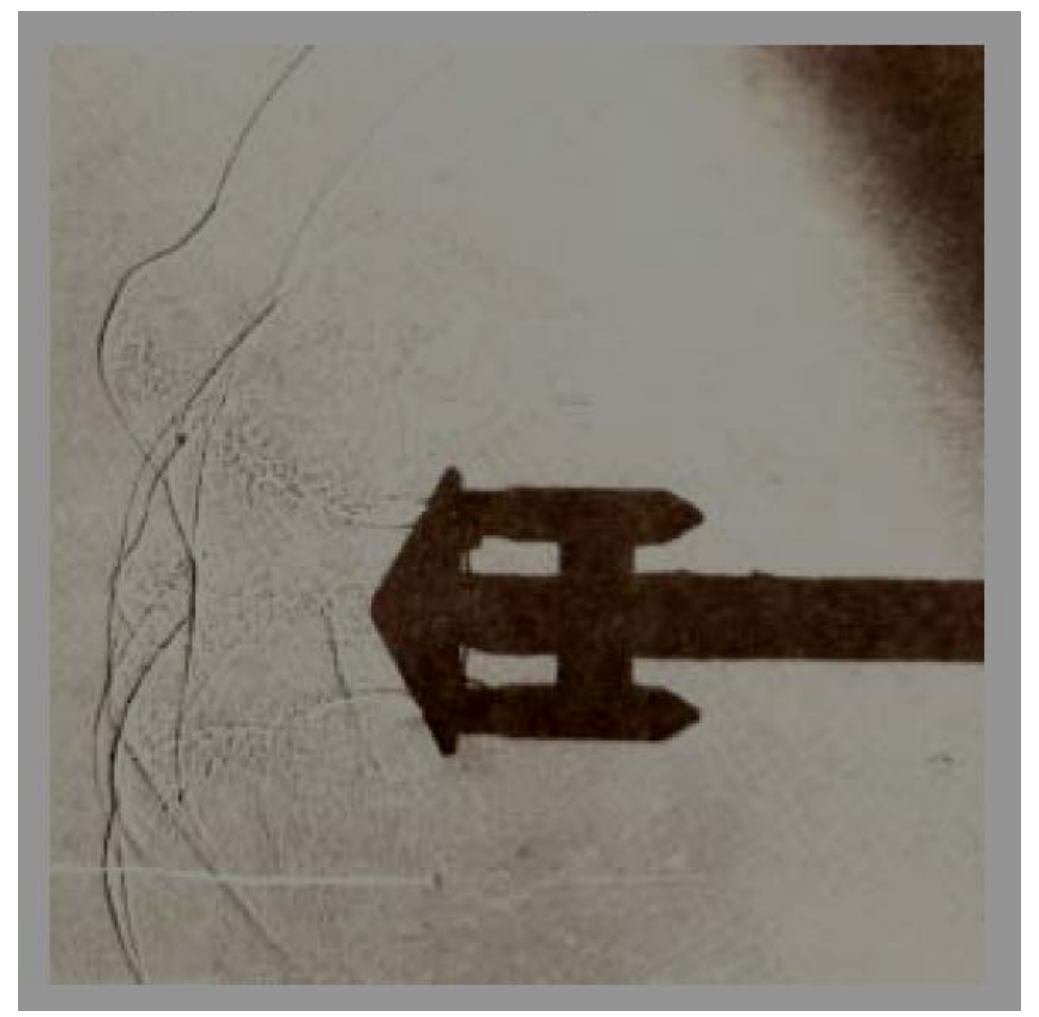

Figure 3. Historical retro-propulsion testing, three engine configuration (Ref. 3, 1970).

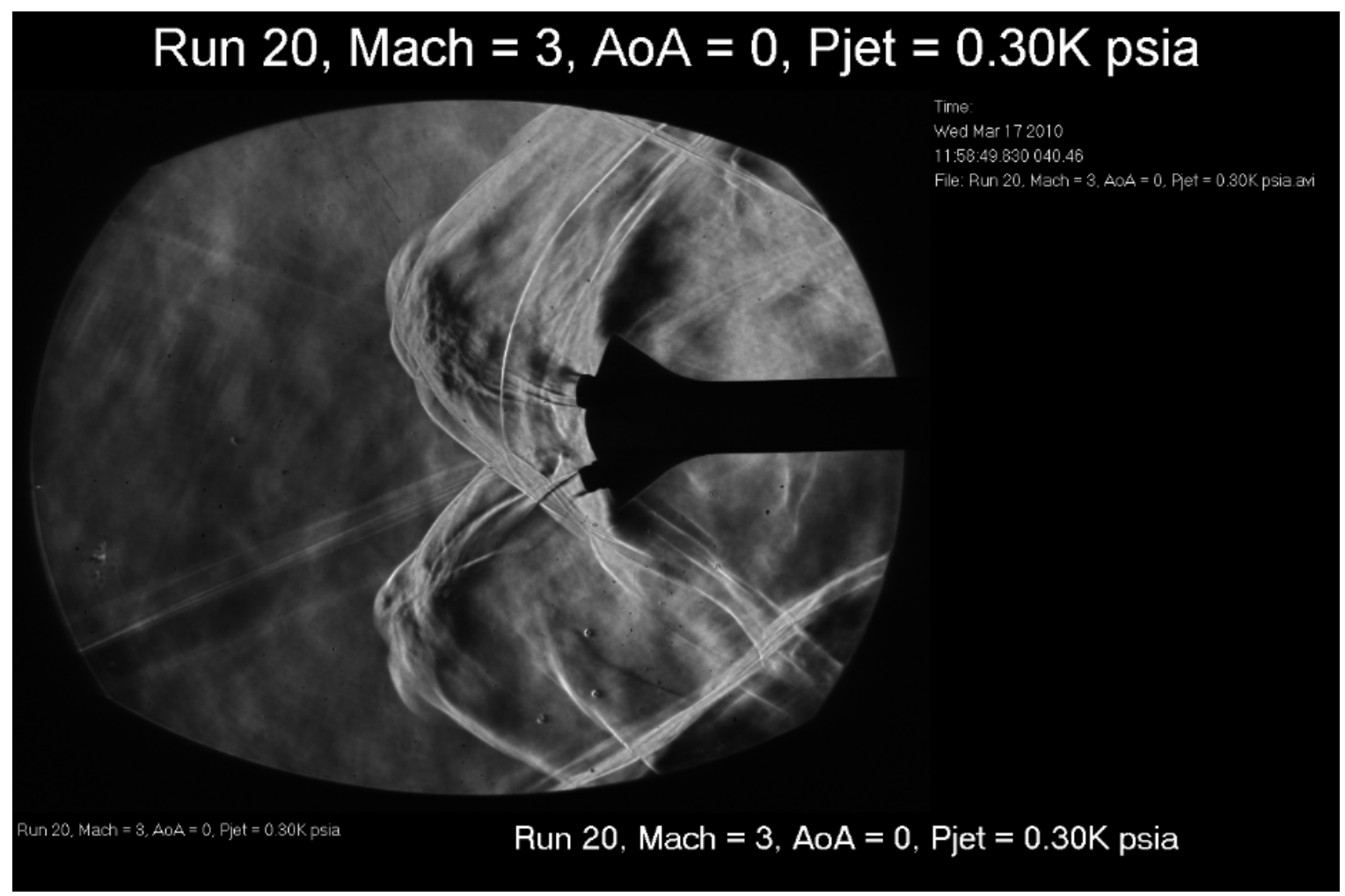

Figure 4. Schlieren image from 1x1 SWT testing - three engine model, Mach $=3.0, \mathrm{Re} / \mathrm{ft}=1.45 \times 10^{6}$, and $\mathrm{P}$, total $(\mathrm{psi})=8.67, \mathrm{AoA}=0$ degrees, 300 psia engine chamber pressure. 


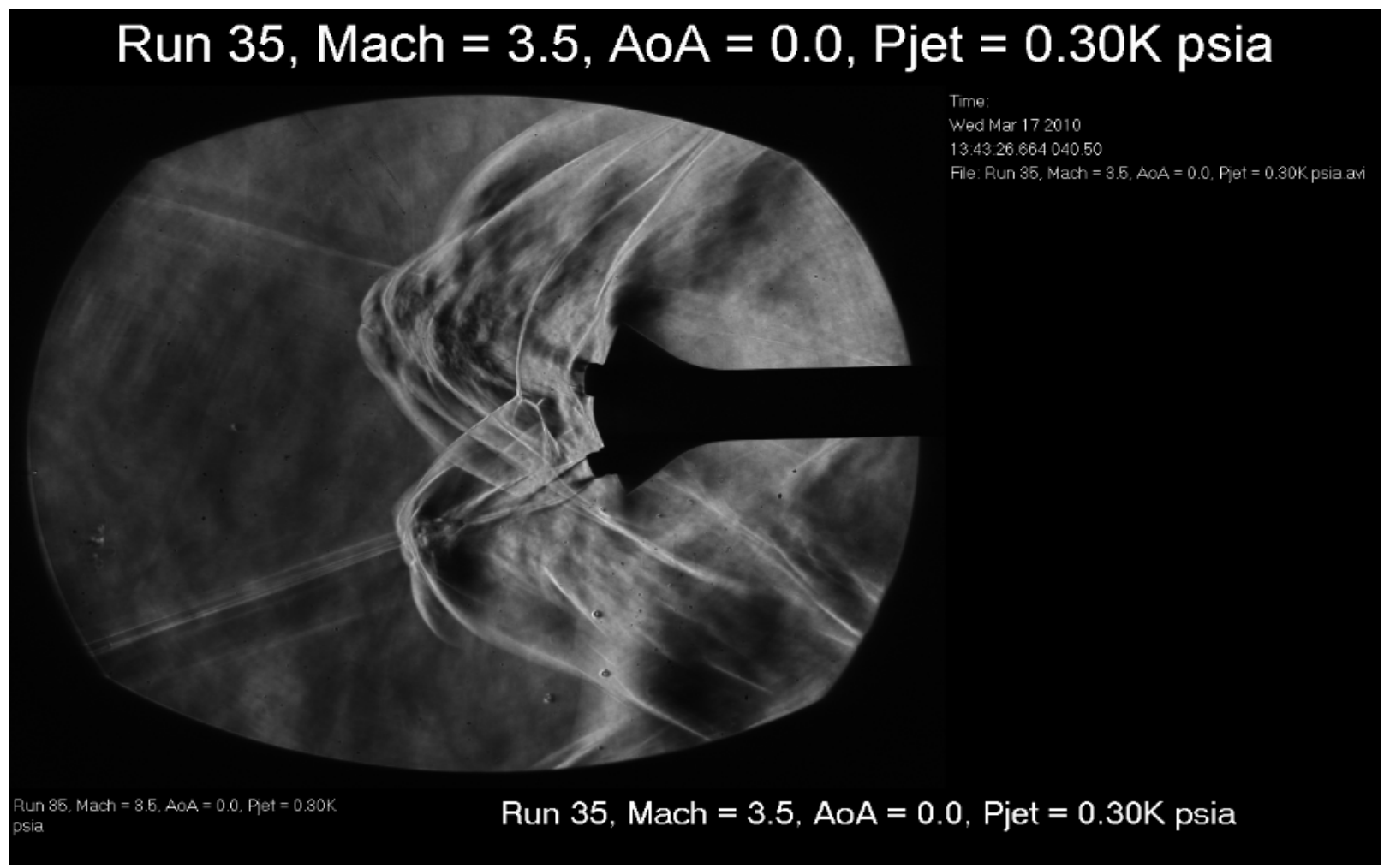

Figure 5. Schlieren image from $1 \times 1$ SWT testing - three engine model, Mach $=3.5, \mathrm{Re} / \mathrm{ft}=1.86 \times 10^{6}$, and $\mathrm{P}$, total $(\mathrm{psi})=15.00, \mathrm{AoA}=0$ degrees, 300 psia engine chamber pressure.

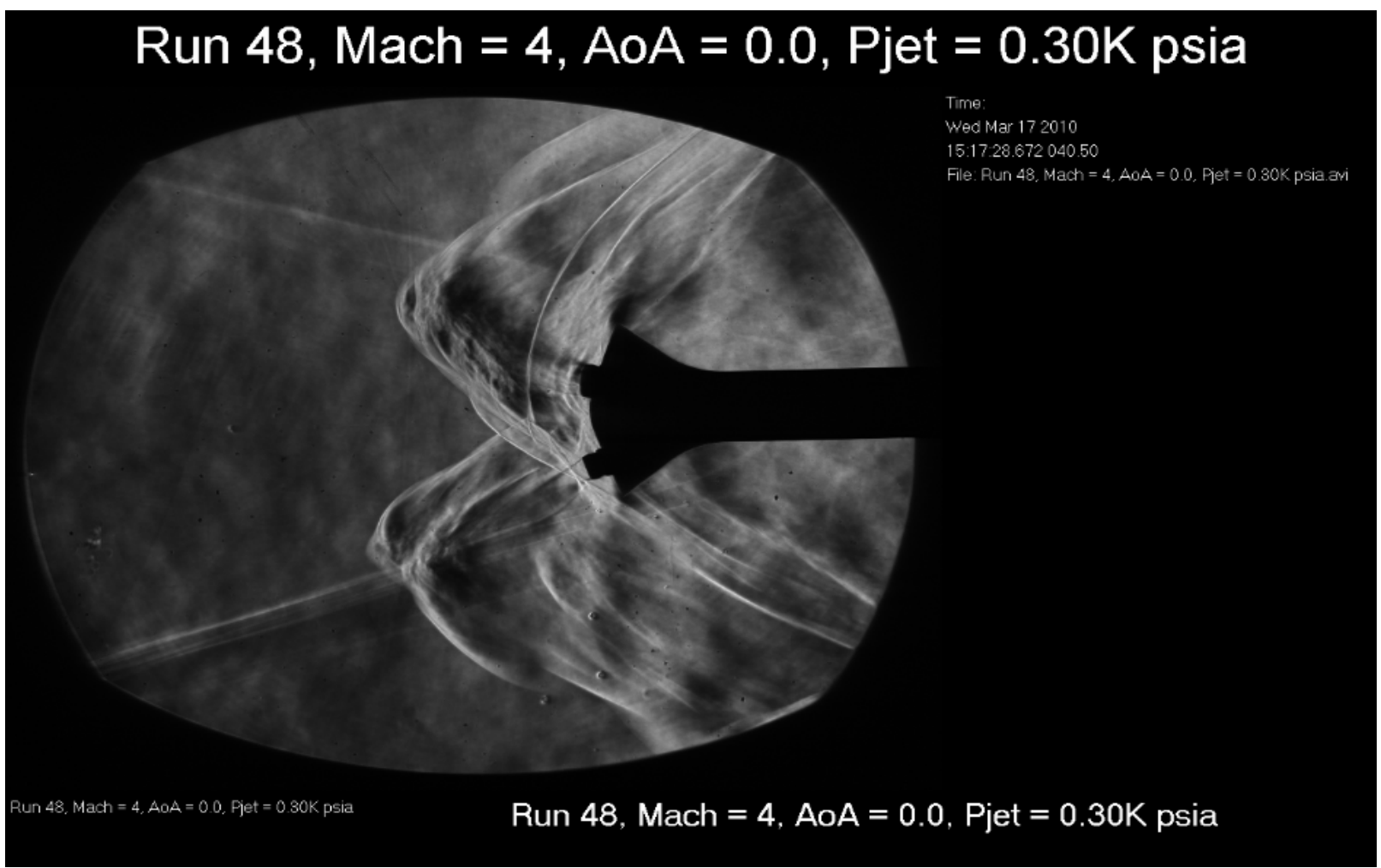

Figure 6. Schlieren image from 1x1 SWT testing - three engine model, Mach $=4.0, \mathrm{Re} / \mathrm{ft}=2.58 \times 10^{6}$, and $\mathrm{P}$, total $(\mathrm{psi})=26.13$, AoA $=0$ degrees, 300 psia engine chamber pressure 


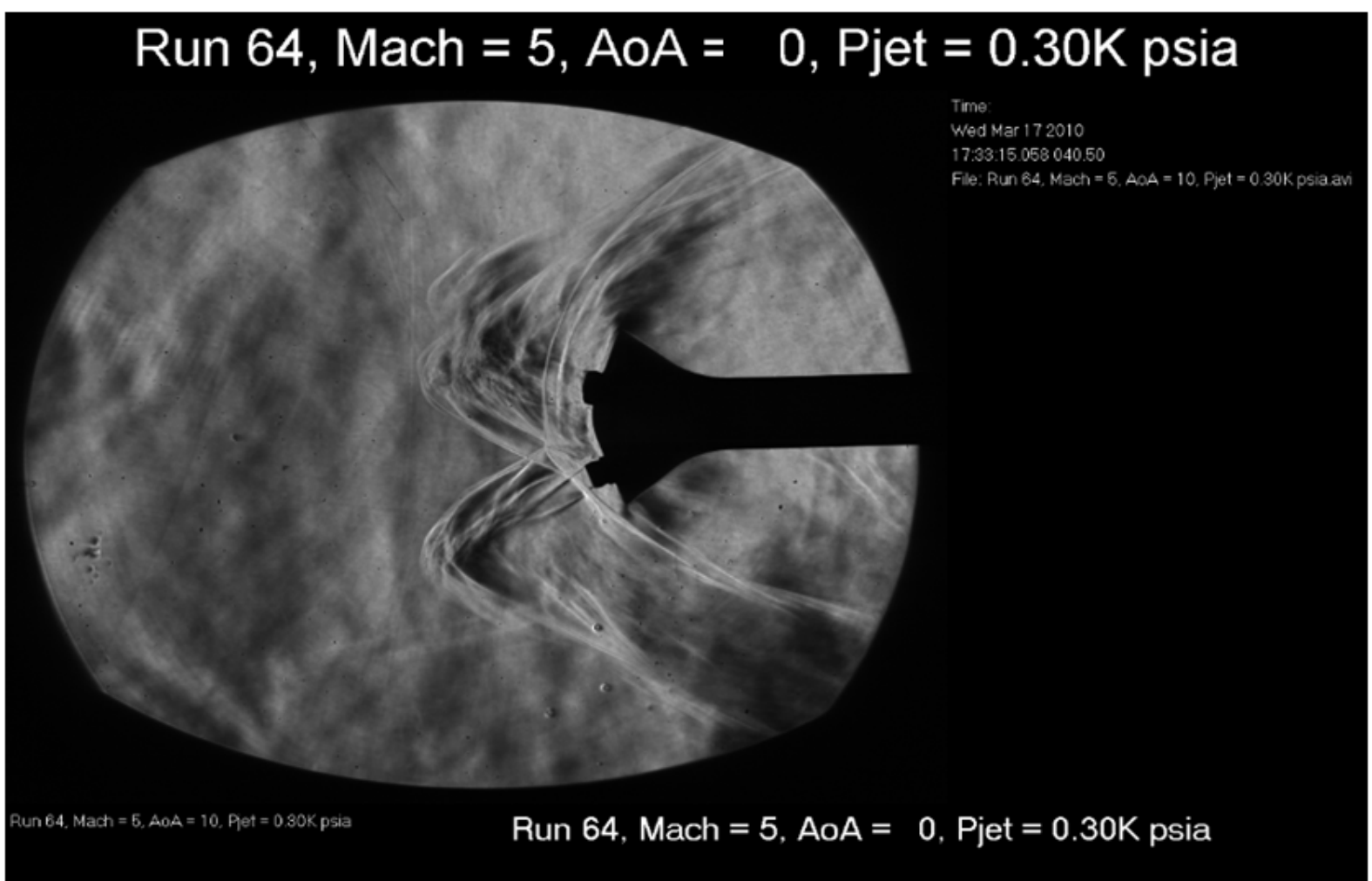

Figure 7. Schlieren image from $1 \times 1$ SWT testing - three engine model, Mach $=5.0, \mathrm{Re} / \mathrm{ft}=5.19 \times 10^{6}$, and $\mathrm{P}$, total $(\mathrm{psi})=92.39$, AoA $=0$ degrees, 300 psia engine chamber pressure.

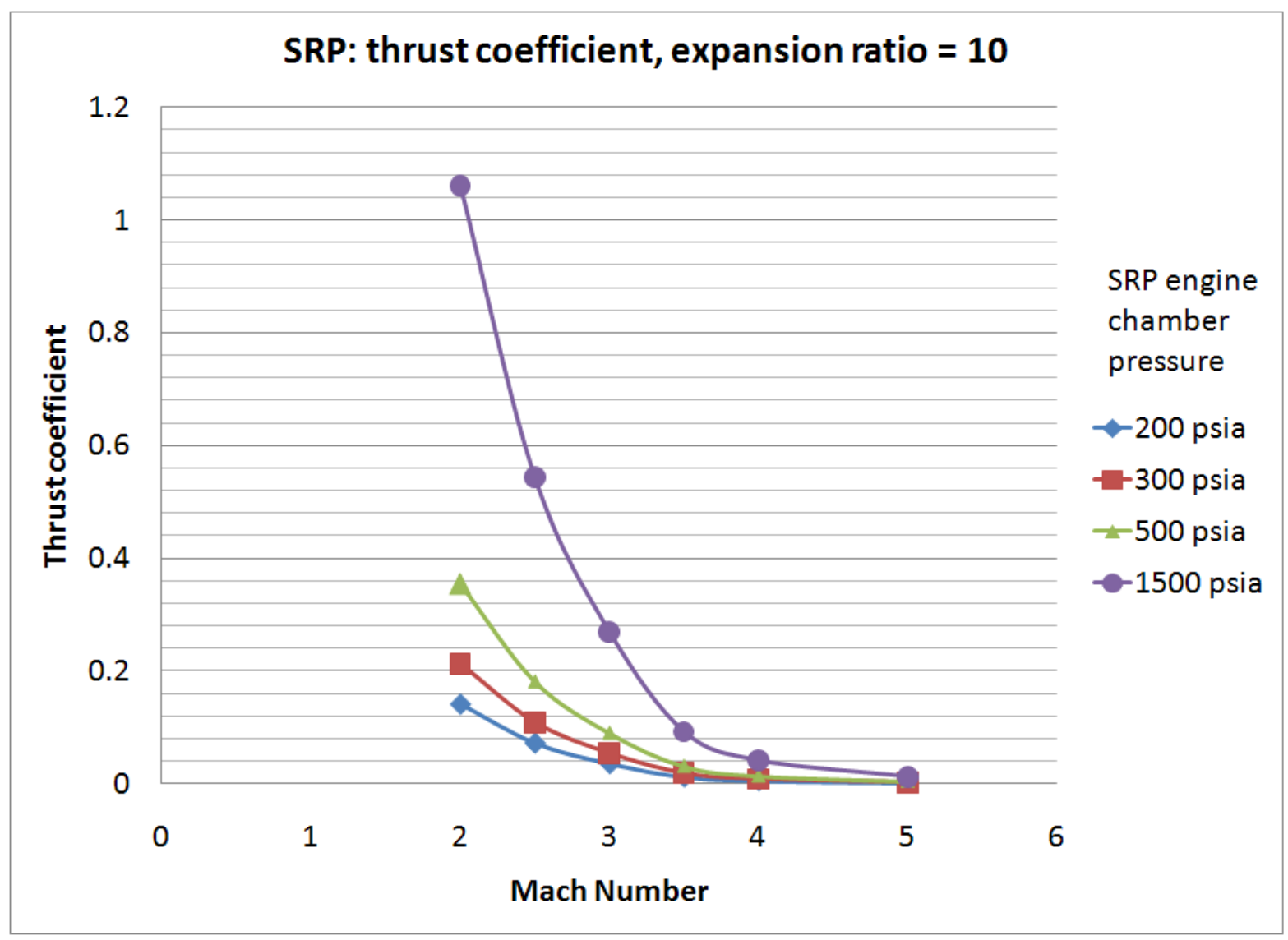

Figure 8. Thrust coefficient versus Mach Number for varying engine chamber pressures. 


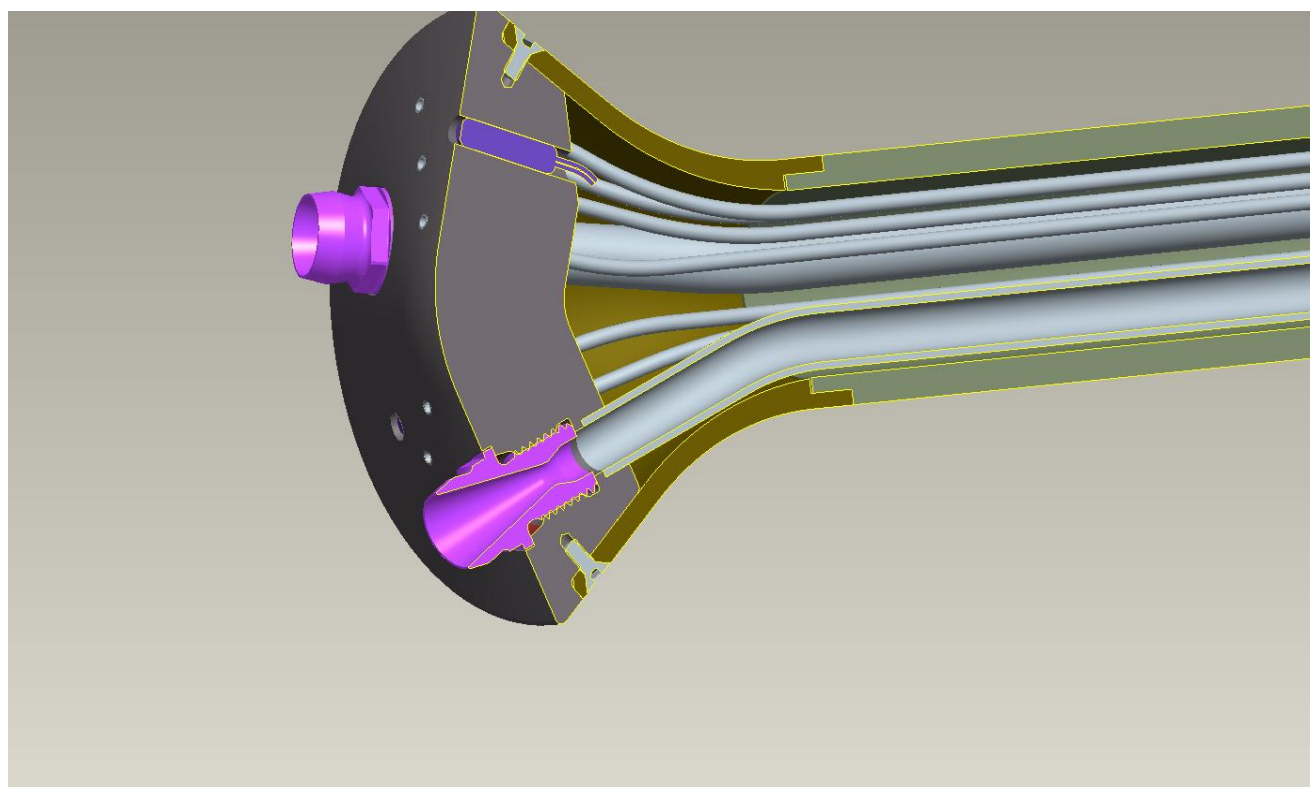

Figure 9. Retro-propulsion model for three engine configuration, with nozzle extensions $($ expansion ratio $=10: 1)$.

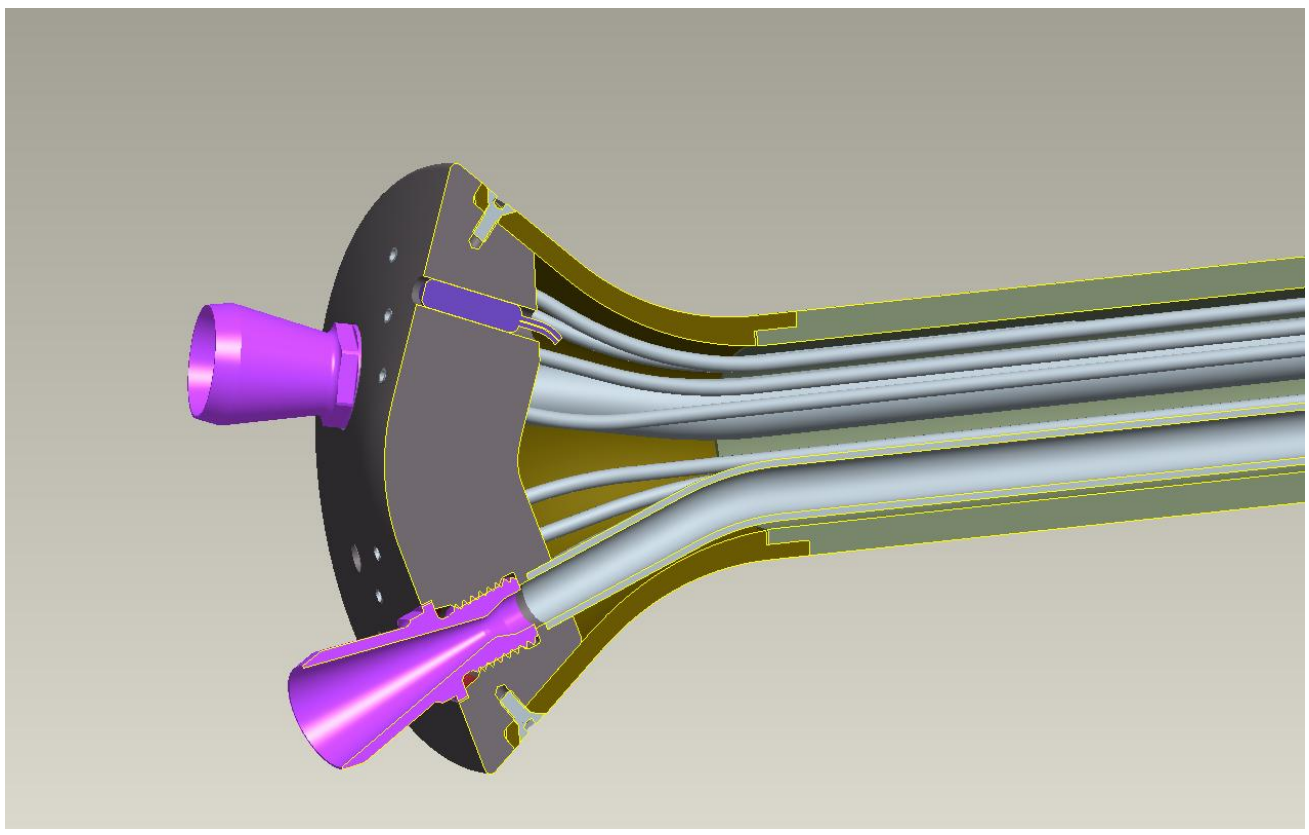

Figure 10. Retro-propulsion model for three engine configuration, with nozzle extensions (expansion ratio $=20: 1)$. 


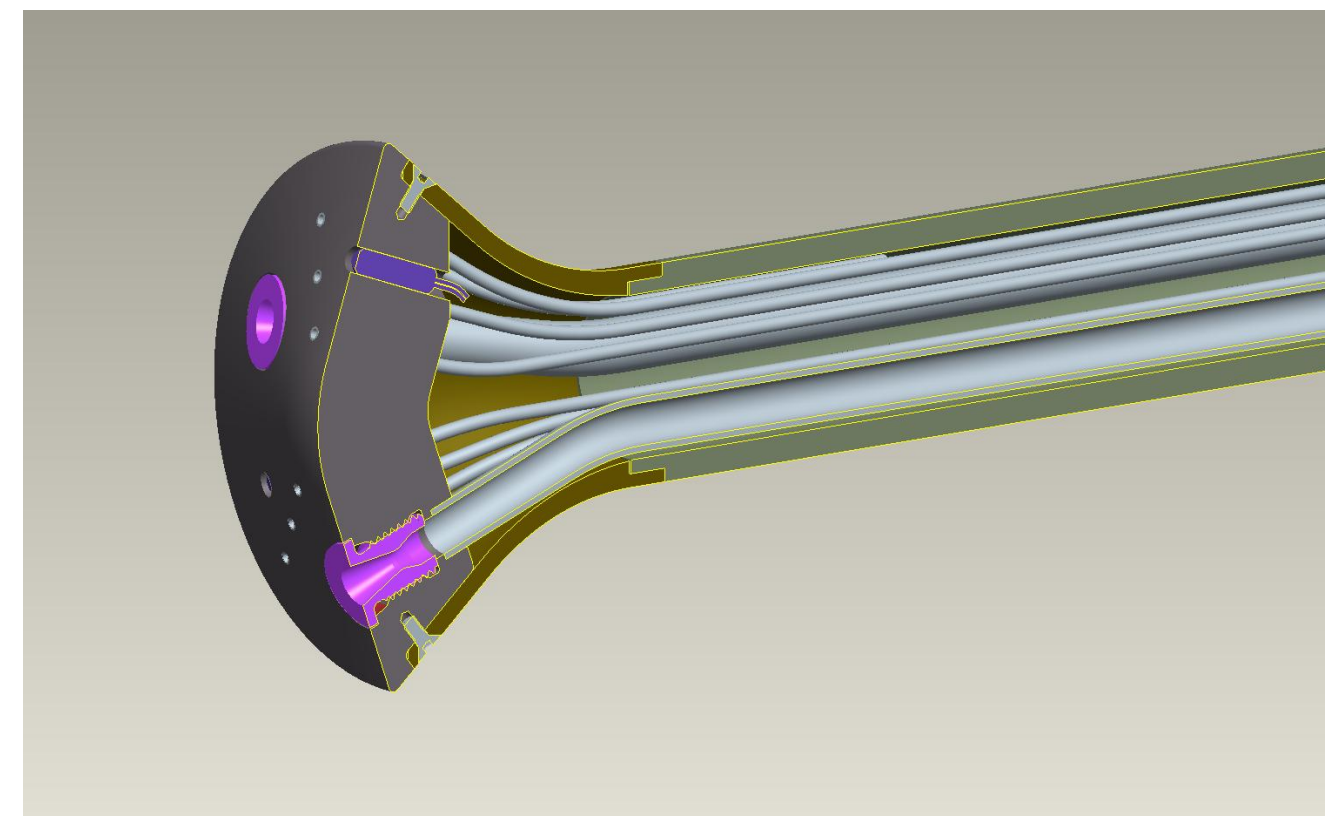

Figure 11. Retro-propulsion model for three engine configuration, with no nozzle extensions (expansion ratio $=4: 1)$.

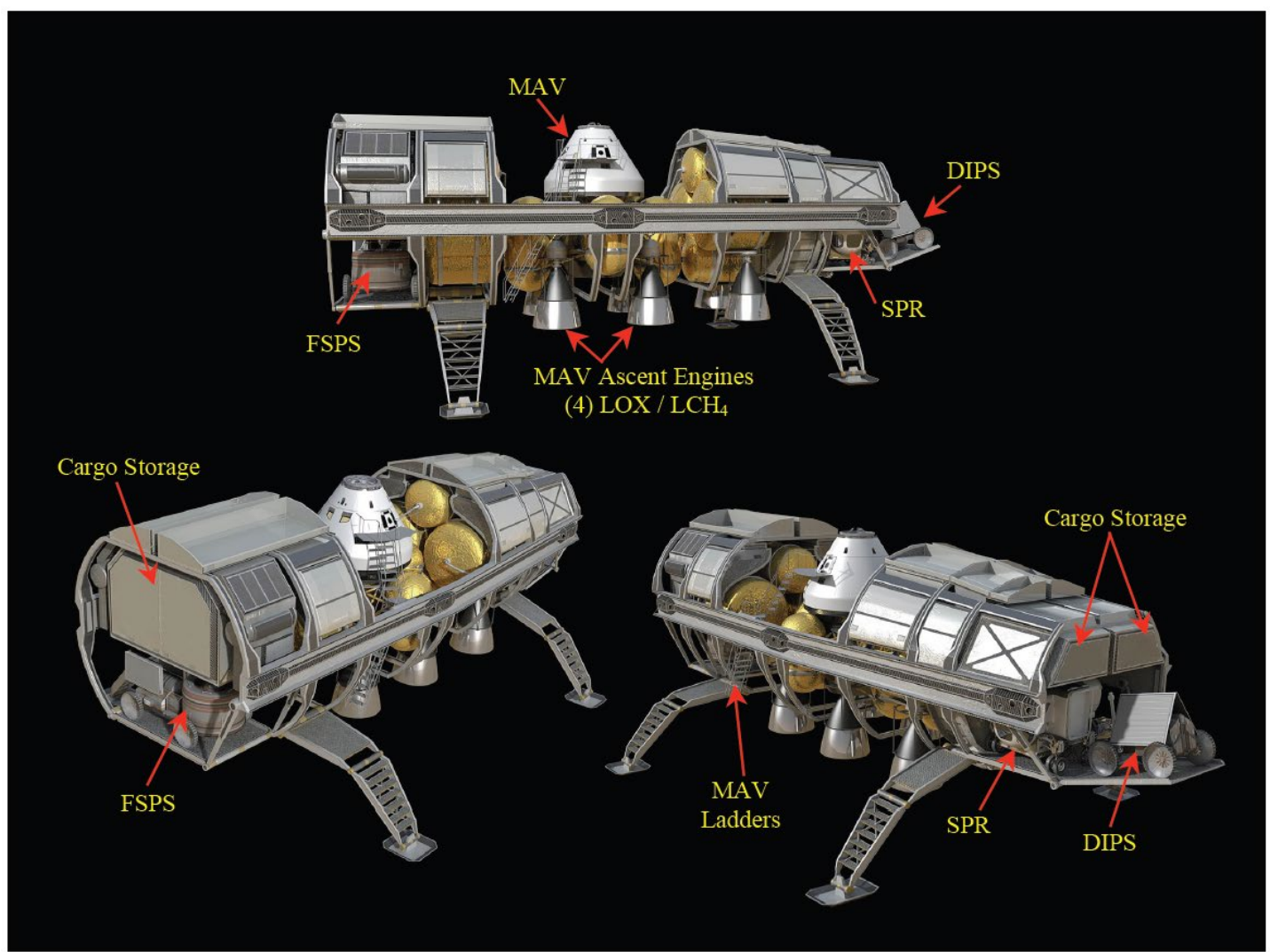

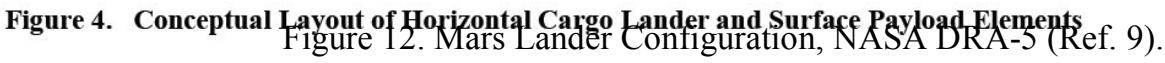


Table I. Overall results of and comments on EDL SRP test matrix (2.5 inch diameter aeroshell model, three engine configuration).

\begin{tabular}{|c|c|c|c|c|c|}
\hline & \multicolumn{4}{|c|}{ NASA EDL SRP $1 \times 1$ SWT test results summary, 03-17-2010 } & \\
\hline Reading & Mach Number & A०A (degrees) & P,jet (psia) & Comment & Specifics \\
\hline 6 & 2.5 & 0 & 200 & $\begin{array}{l}\text { Some strong wall } \\
\text { interaction }\end{array}$ & Some strong wall interactions \\
\hline 9 & 2.5 & 0 & 300 & $\begin{array}{l}\text { Tunnel Unstart, } \\
\text { with Recovery }\end{array}$ & $\begin{array}{l}\text { Post firing: this firing is a potential unstart, with the } \\
\text { tunnel taking a few seconds to recover the full Mach } \\
\text { Number after the engines are turned off. }\end{array}$ \\
\hline 10 & 2.5 & 0 & 500 & $\begin{array}{l}\text { Tunnel Unstart, } \\
\text { with Recovery }\end{array}$ & $\begin{array}{l}\text { Post firing: this firing is a potential unstart, with the } \\
\text { tunnel recovering the full Mach Number flow after } \\
\text { the engines are turned off. }\end{array}$ \\
\hline 7 & 2.5 & 10 & 200 & $\begin{array}{l}\text { Some strong wall } \\
\text { interaction }\end{array}$ & Some strong wall interaction \\
\hline 8 & 2.5 & 10 & 300 & $\begin{array}{l}\text { Tunnel Unstart, } \\
\text { with Recovery }\end{array}$ & $\begin{array}{l}\text { Post firing: this firing is a potential unstart, with the } \\
\text { tunnel recovering the full Mach Number flow after } \\
\text { the engines are turned off. }\end{array}$ \\
\hline 11 & 2.5 & 10 & 500 & $\begin{array}{l}\text { Tunnel Unstart, } \\
\text { with Recovery }\end{array}$ & $\begin{array}{l}\text { Post firing: this firing is a potential unstart, with the } \\
\text { tunnel recovering the full Mach Number flow after } \\
\text { the engines are turned off. }\end{array}$ \\
\hline & & & & & \\
\hline Reading & Mach Number & AoA (degrees) & P,jet (psia) & Comment & Specifics \\
\hline 19 & 3.0 & 0 & 200 & Spectacular & Minor wall interactions \\
\hline 20 & 3.0 & 0 & 300 & Spectacular & Some strong wall interactions \\
\hline 23 & 3.0 & 0 & 500 & $\begin{array}{l}\text { Tunnel Unstart, } \\
\text { with Recovery }\end{array}$ & $\begin{array}{l}\text { Post firing: this firing is a potential unstart, with the } \\
\text { tunnel recovering the full Mach Number flow after } \\
\text { the engines are turned off. }\end{array}$ \\
\hline $16 \mathrm{~A}, 17$ & 3.0 & 10 & 200 & Spectacular & Minor wall interactions \\
\hline 21 & 3.0 & 10 & 300 & Spectacular & Minor wall interactions \\
\hline 22 & 3.0 & 10 & 500 & $\begin{array}{l}\text { Tunnel Unstart, } \\
\text { with Recovery }\end{array}$ & $\begin{array}{l}\text { Post firing: this firing is a potential unstart, with the } \\
\text { tunnel recovering the full Mach Number flow after } \\
\text { the engines are turned off. }\end{array}$ \\
\hline 24 & 3.0 & 15 & 500 & $\begin{array}{l}\text { Tunnel Unstart, } \\
\text { with Recovery }\end{array}$ & $\begin{array}{l}\text { Post firing: this firing is a potential unstart, with the } \\
\text { tunnel recovering the full Mach Number flow after } \\
\text { the engines are turned off. }\end{array}$ \\
\hline & & & & & \\
\hline Reading & Mach Number & AoA (degrees) & P,jet (psia) & Comment & Specifics \\
\hline 30 & 3.5 & 0 & 200 & Spectacular & No wall interactions \\
\hline 35 & 3.5 & 0 & 300 & Spectacular & No wall interactions \\
\hline 39 & 3.5 & 0 & 500 & Spectacular & No wall interactions* \\
\hline 31 & 3.5 & 10 & 200 & Spectacular & No wall interactions \\
\hline 34 & 3.5 & 10 & 300 & Spectacular & No wall interactions \\
\hline 38 & 3.5 & 10 & 500 & Spectacular & No wall interactions* \\
\hline no reading & 3.5 & 15 & 200 & $\begin{array}{l}\text { No data point } \\
\text { taken }\end{array}$ & No data point taken \\
\hline 36 & 3.5 & 15 & 300 & Spectacular & No wall interactions \\
\hline 37 & 3.5 & 15 & 500 & Spectacular & No wall interactions* \\
\hline & & & & & \\
\hline Reading & Mach Number & AoA (degrees) & P,jet (psia) & Comment & Specifics \\
\hline 43 & 4.0 & 0 & 200 & Spectacular & No wall interactions \\
\hline 48 & 4.0 & 0 & 300 & Spectacular & Some wall interactions \\
\hline 49 & 4.0 & 0 & 500 & Spectacular & Minor wall interactions \\
\hline 44 & 4.0 & 10 & 200 & Spectacular & Minor wall interactions, far downstream \\
\hline 47 & 4.0 & 10 & 300 & Spectacular & No wall interactions \\
\hline 50 & 4.0 & 10 & 500 & Spectacular & Minor wall interactions \\
\hline 45 & 4.0 & 15 & 200 & Spectacular & Minor wall interactions, far downstream \\
\hline 46 & 4.0 & 15 & 300 & Spectacular & Minor wall interactions, far downstream \\
\hline 51 & 4.0 & 15 & 500 & Spectacular & Minor wall interactions, downstream, near backshell \\
\hline Reading & Mach Number & AoA (degrees) & P,jet (psia) & Comment & Specifics \\
\hline 63 & 5.0 & 0 & 200 & Spectacular & $\begin{array}{l}\text { No wall interactions. Required Heater Usage, } T= \\
300 \mathrm{~F} \text { to establish stable shock on the model. Heater } \\
\text { used in all } M=5.0 \text { tests }\end{array}$ \\
\hline 64 & 5.0 & 0 & 300 & Spectacular & No wall interactions \\
\hline 65 & 5.0 & 0 & 500 & Spectacular & Minor wall interactions \\
\hline 62 & 5.0 & 10 & 200 & Spectacular & No wall interactions \\
\hline 61 & 5.0 & 10 & 300 & Spectacular & No wall interactions \\
\hline 60 & 5.0 & 10 & 500 & Spectacular & No wall interactions \\
\hline 57 & 5.0 & 15 & 200 & Spectacular & No wall interactions \\
\hline 58 & 5.0 & 15 & 300 & Spectacular & No wall interactions \\
\hline 59 & 5.0 & 15 & 500 & Spectacular & No wall interactions \\
\hline
\end{tabular}




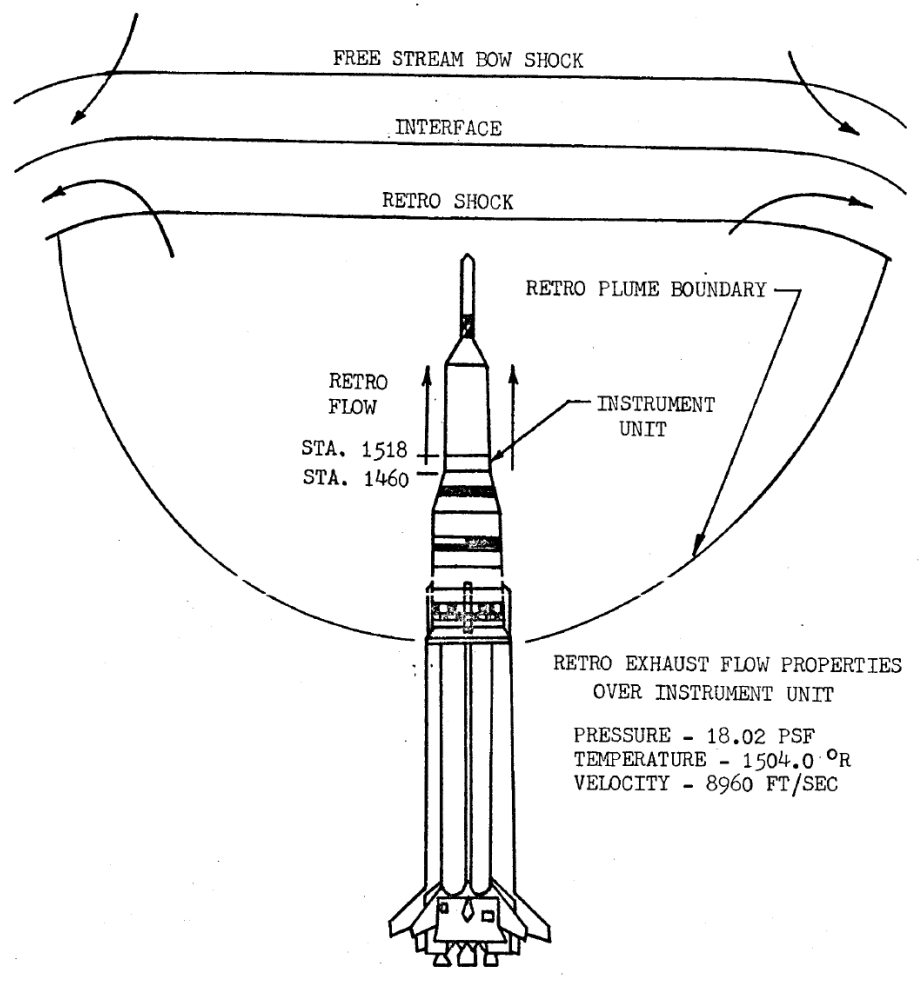

Figure 13. Saturn I Launch Vehicle Retrorocket Flowfield Model (Ref. 10).

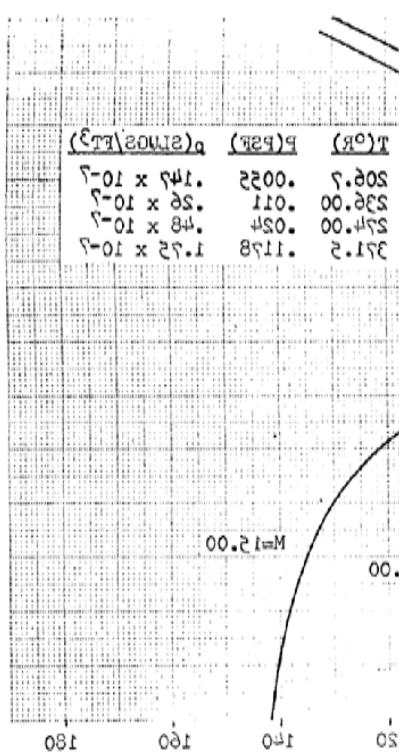

Igbom

Figure 14. Saturn I Launch Vehicle Retrorocket Plume Size Prediction (Ref. 10). 


\section{Rocket-Back Trajectory}

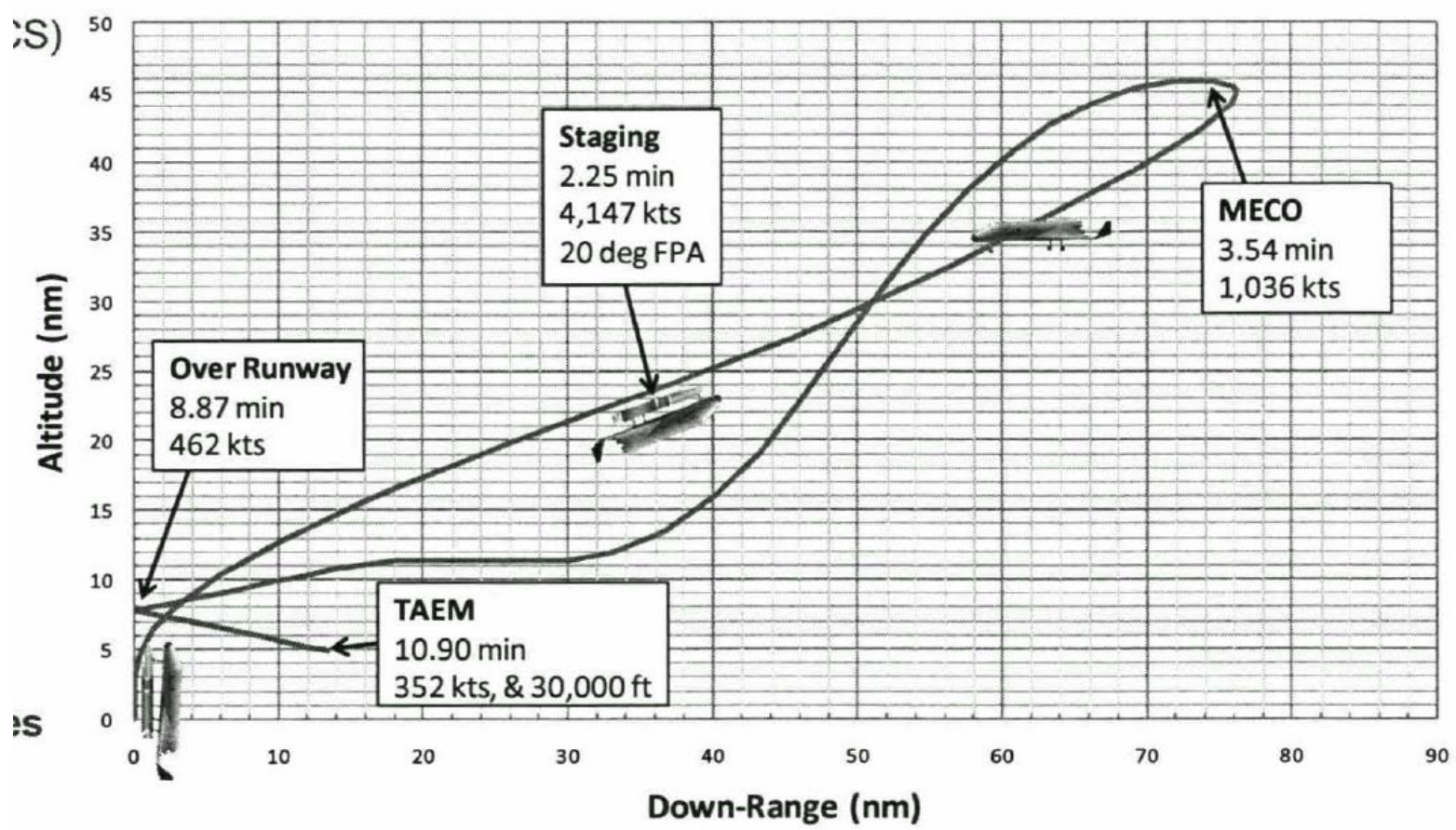

Figure 15. Reusable Booster System Flight Path with Rocket Back Maneuver (Ref. 11).
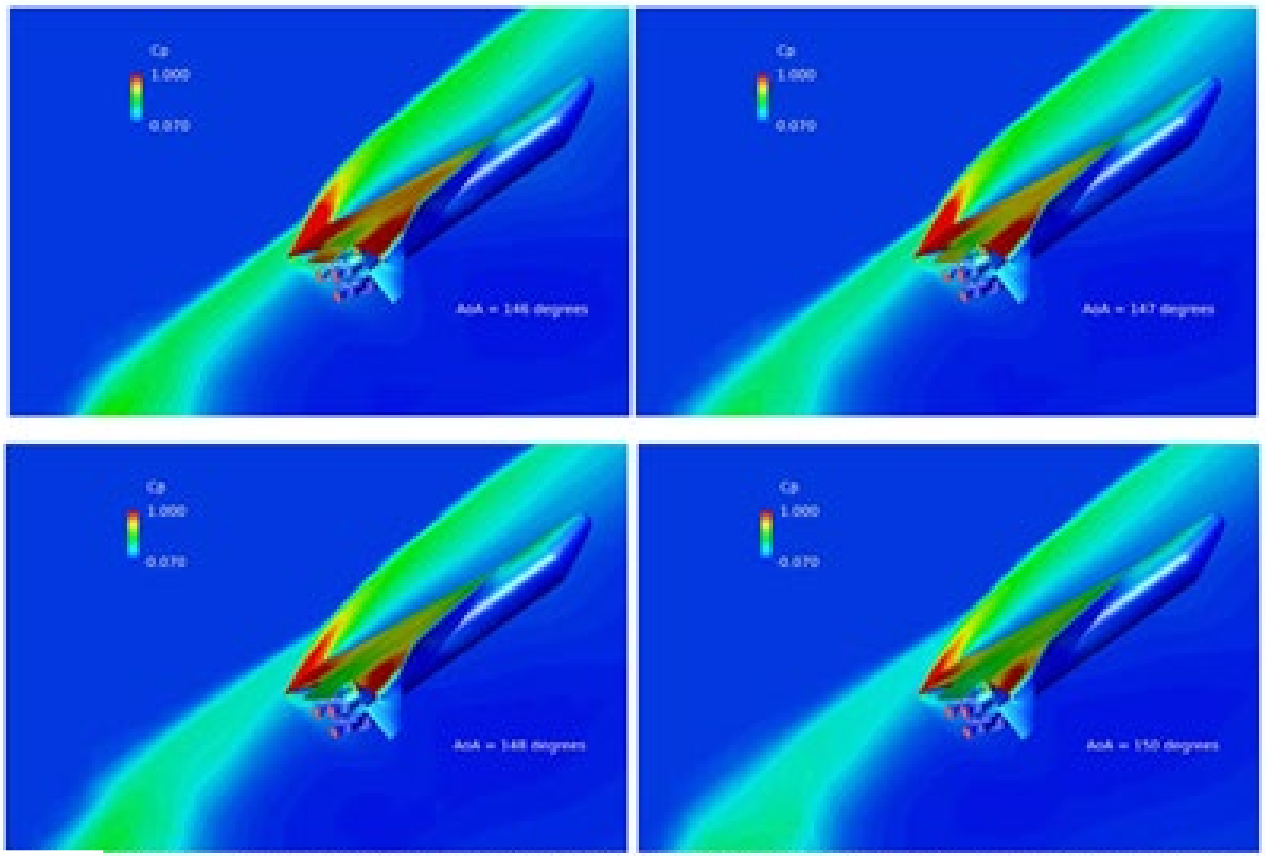

Steady-state $C_{p}$ Values on Vehicle and Off-body Mid-span Plane for Four Angles of Attack, MI = 4.5, $Q=100 \mathrm{psf}$

Figure 16. Reusable Booster System Cp Predictions for 4 Angles of Attack (Ref. 12) 


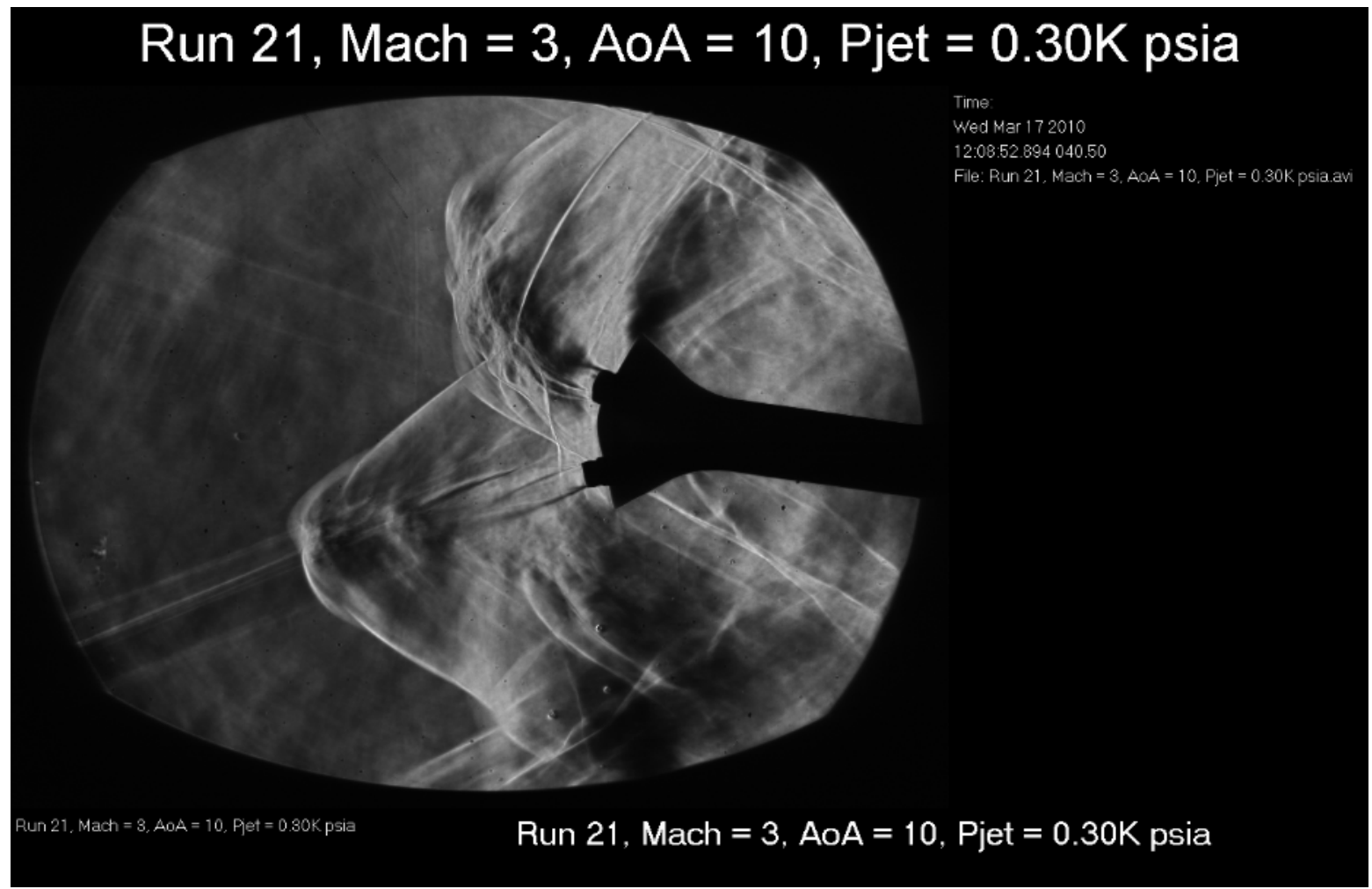

Figure A1-2. Schlieren image from 1x1 SWT testing - three engine model, Mach $=3.0, \mathrm{Re} / \mathrm{ft}=1.42 \times 10^{6}$, and $\mathrm{P}$, total $(\mathrm{psi})=8.49, \mathrm{AoA}=10$ degrees, 300 psia engine chamber pressure.

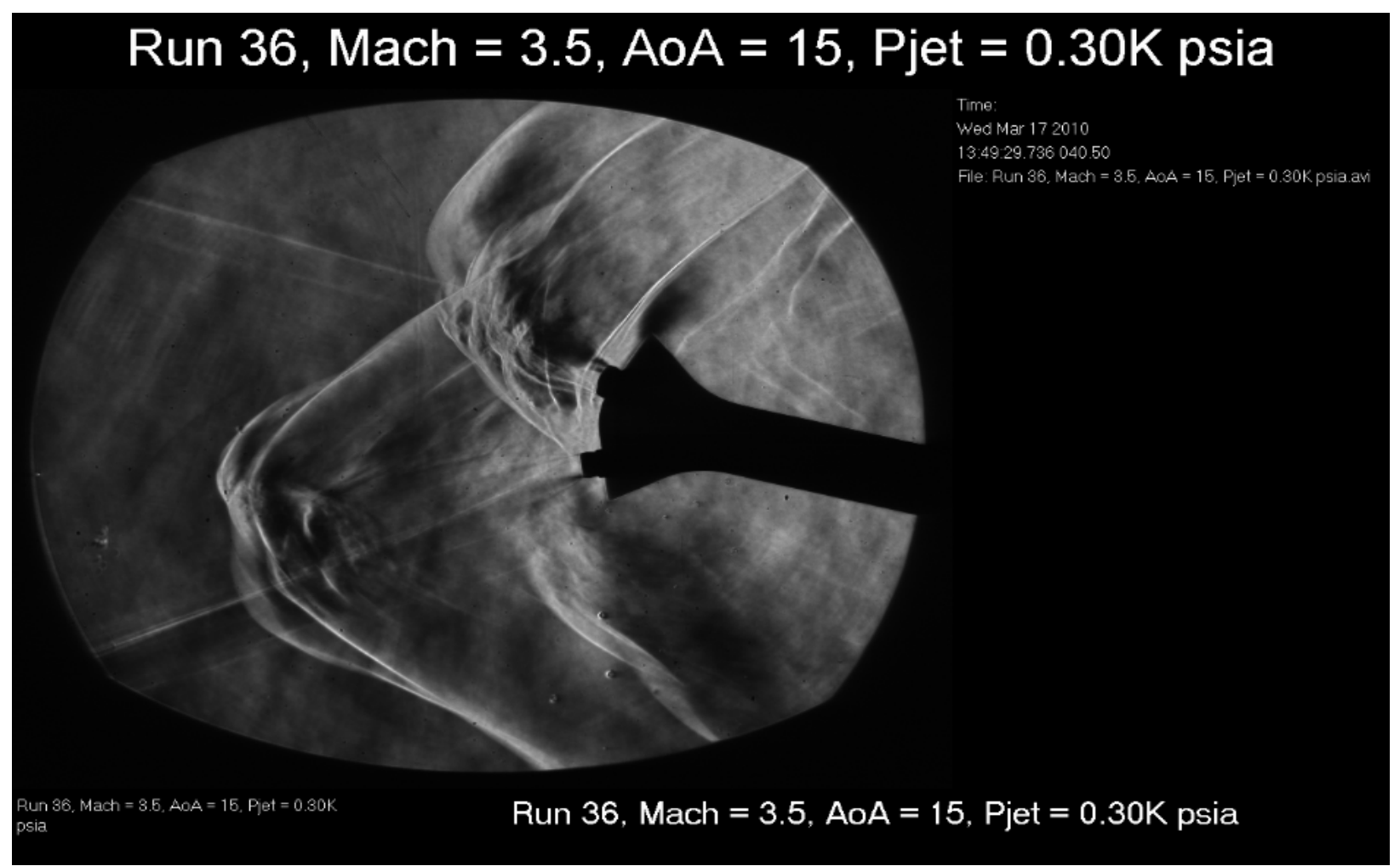

Figure A1-3. Schlieren image from 1x1 SWT testing - three engine model, Mach $=3.5, \mathrm{Re} / \mathrm{ft}=1.87 \times 10^{6}$, and $\mathrm{P}$, total $(\mathrm{psi})=15.03, \mathrm{AoA}=15$ degrees, 300 psia engine chamber pressure. 
Appendix A1: AoA = 10 degrees (15 degrees, in some cases), 300 psia chamber pressure (continued)

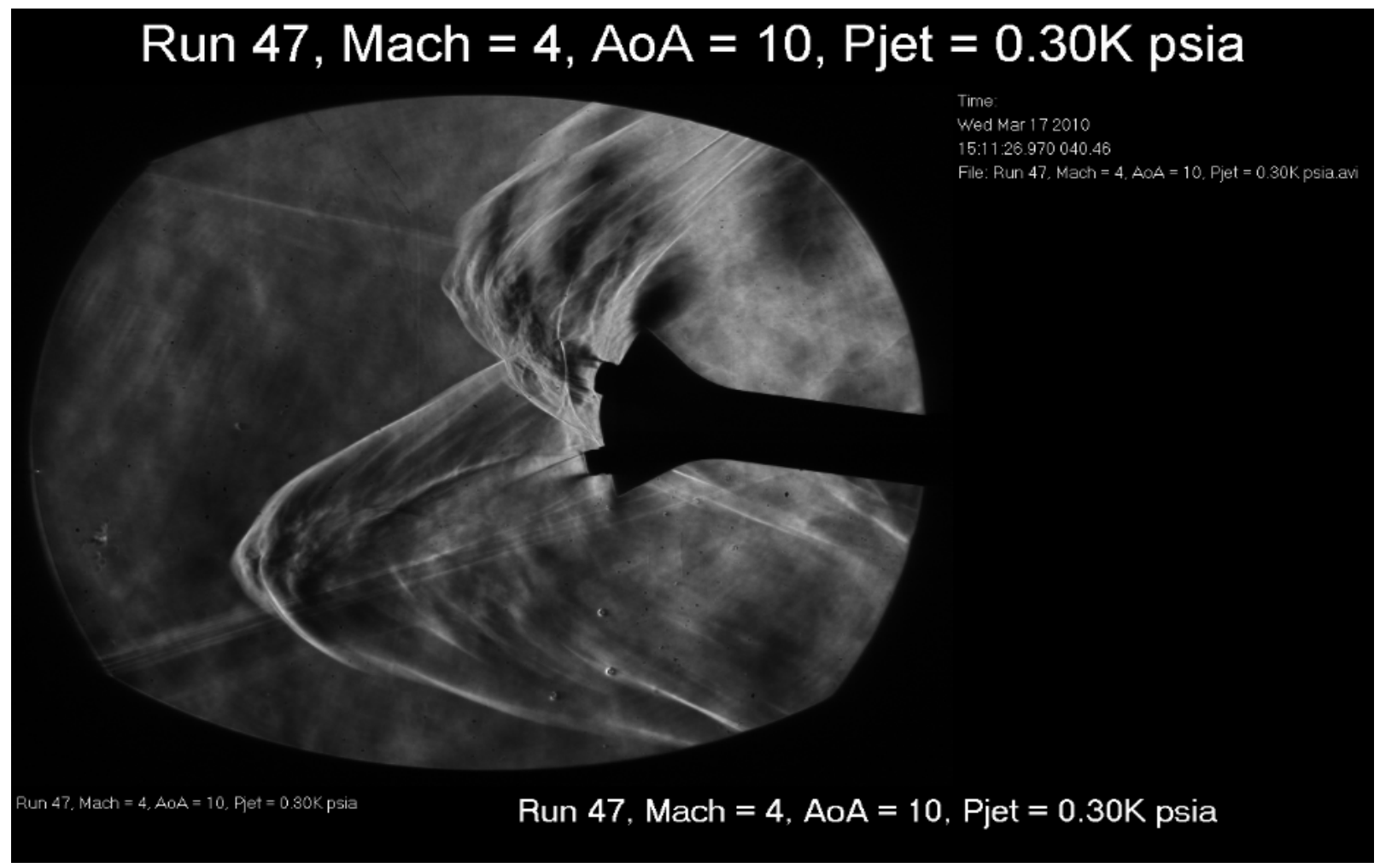

Figure A1-4. Schlieren image from 1x1 SWT testing - three engine model, Mach $=4.0, \mathrm{Re} / \mathrm{ft}=2.57 \times 10^{6}$, and $\mathrm{P}$, total $(\mathrm{psi})=25.94, \mathrm{AoA}=10$ degrees, 300 psia engine chamber pressure.

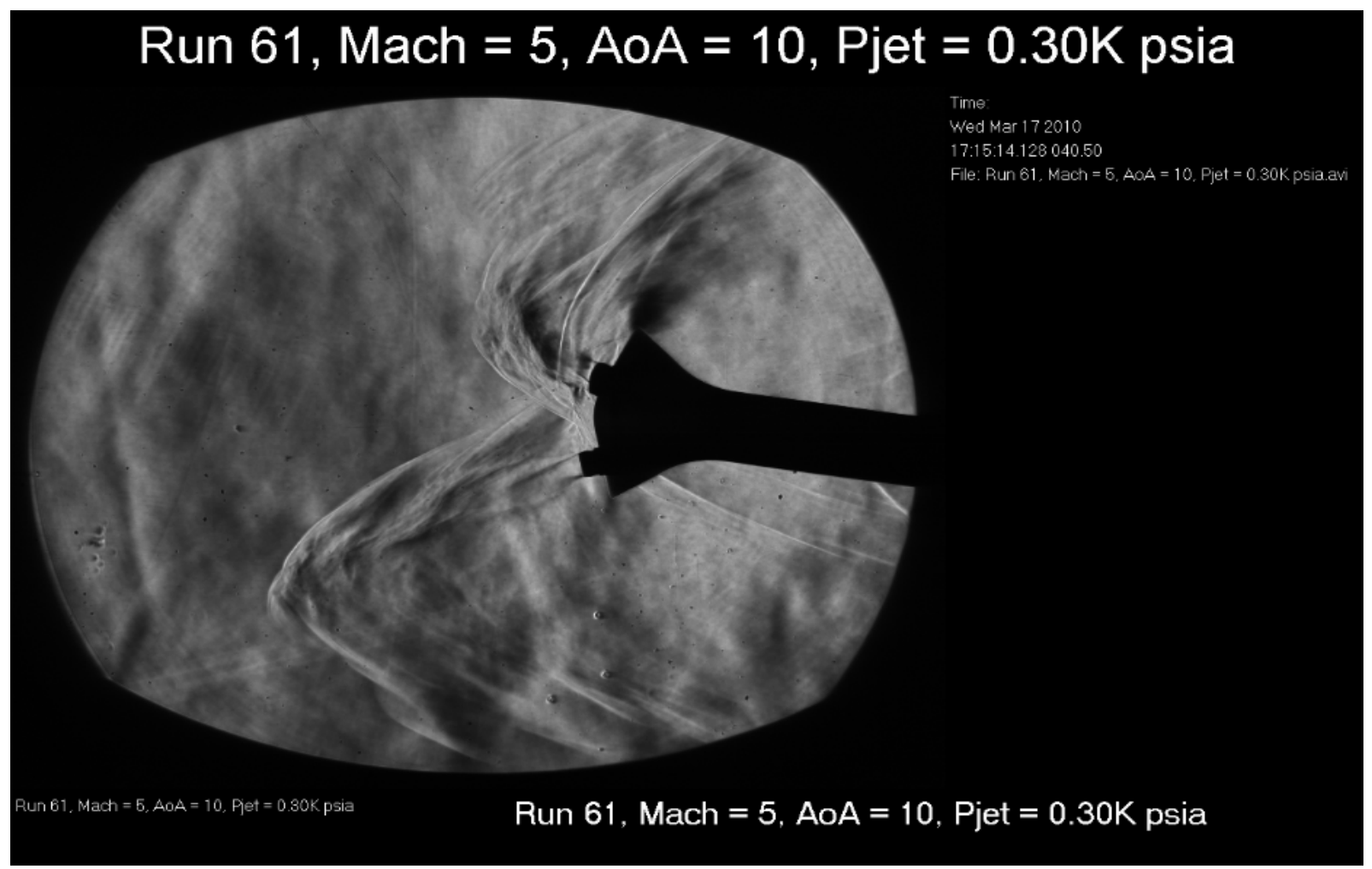

Figure A1-5. Schlieren image from 1x1 SWT testing - three engine model, Mach $=5.0, \operatorname{Re} / \mathrm{ft}=5.32 \times 10^{6}$, and $\mathrm{P}$, total $(\mathrm{psi})=90.37, \mathrm{AoA}=10$ degrees, 300 psia engine chamber pressure. 


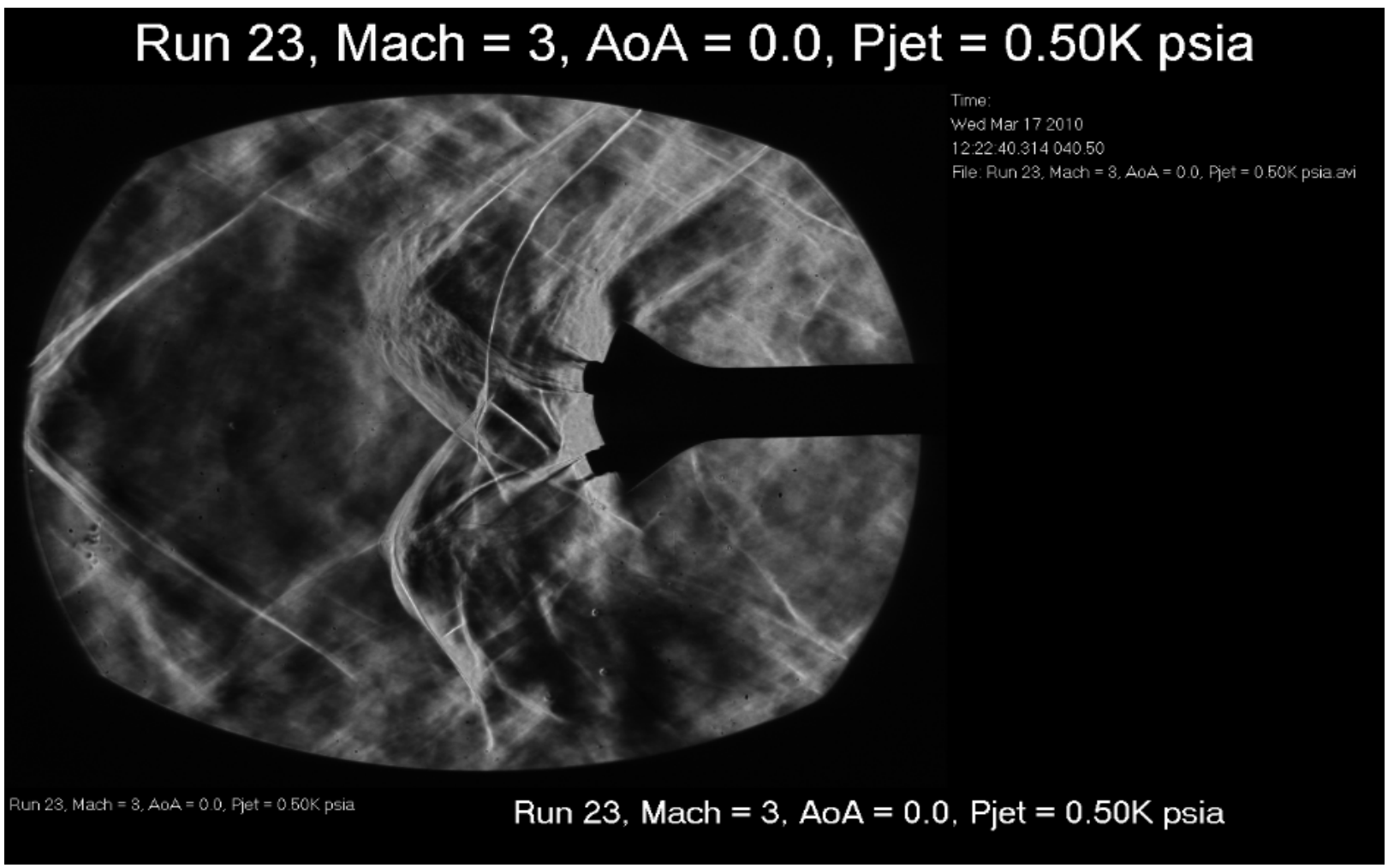

Figure A2-1. Schlieren image from 1x1 SWT testing - three engine model, Mach $=3.0, \mathrm{Re} / \mathrm{ft}=1.50 \times 10^{6}$, and $\mathrm{P}$, total $(\mathrm{psi})=8.95$, AoA $=0$ degrees, 500 psia engine chamber pressure, tunnel unstart.

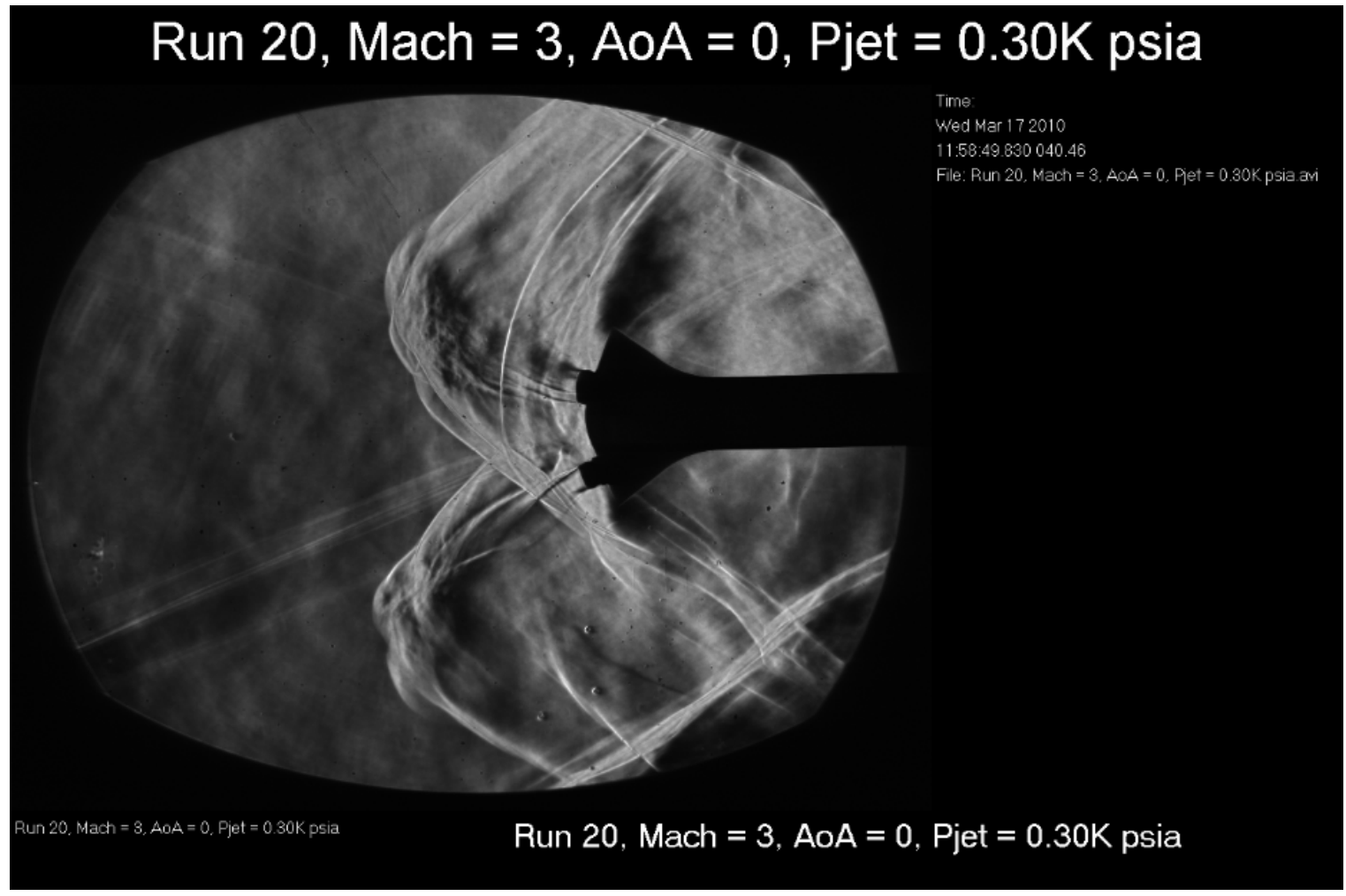

Figure A2-2. Schlieren image from 1x1 SWT testing - three engine model, Mach $=3.0, \mathrm{Re} / \mathrm{ft}=1.45 \times 10^{6}$, and $\mathrm{P}$, total $(\mathrm{psi})=8.67, \mathrm{AoA}=0$ degrees, 300 psia engine chamber pressure. 


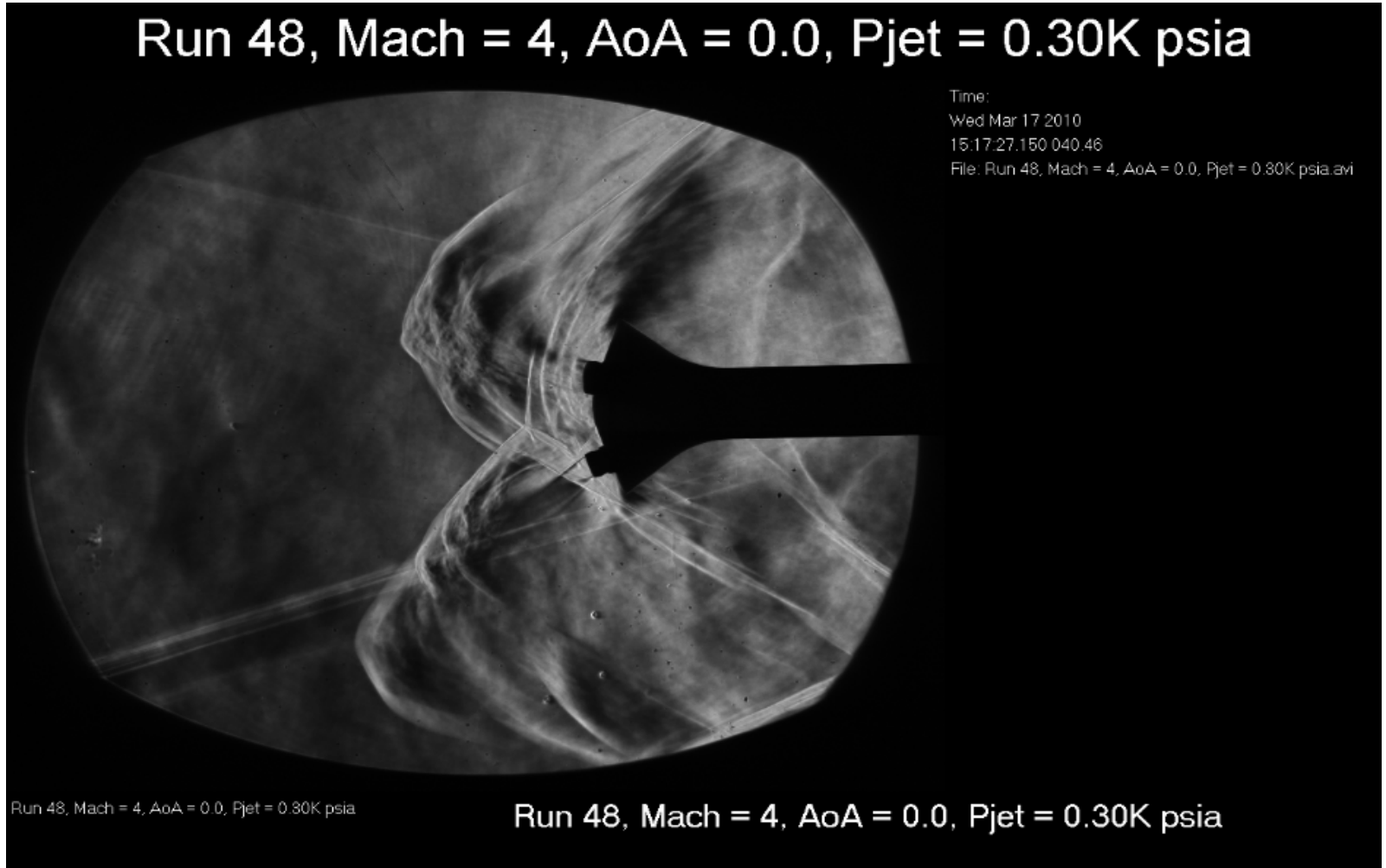

Figure A2-3. Schlieren image from 1x1 SWT testing - three engine model, Mach $=4.0, \mathrm{Re} / \mathrm{ft}=2.60 \times 10^{6}$, and $\mathrm{P}$, total $(\mathrm{psi})=26.33, \mathrm{AoA}=0$ degrees, 300 psia engine chamber pressure.

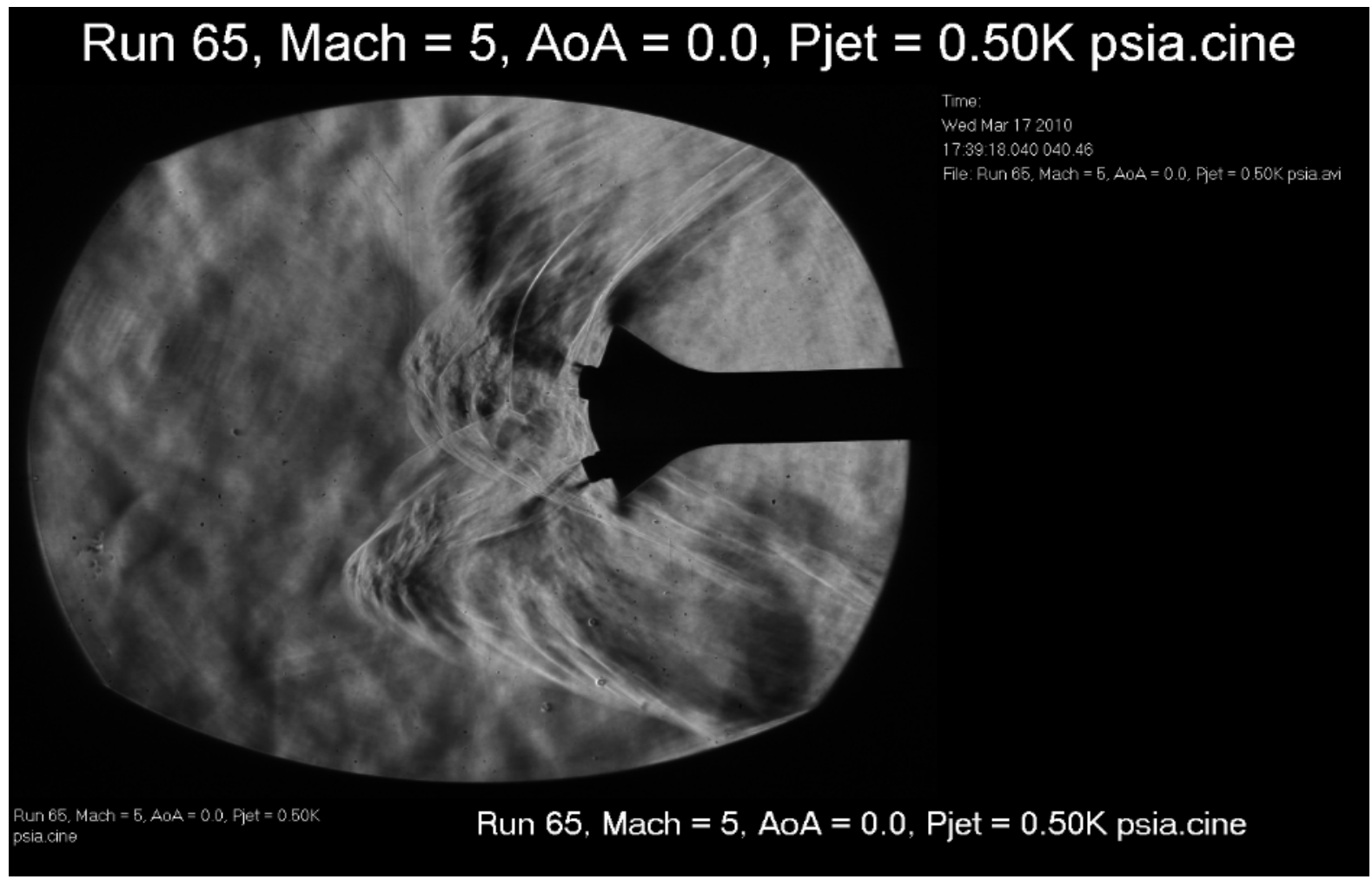

Figure A2-4. Schlieren image from 1x1 SWT testing - three engine model, Mach = 5.0, Re/ft $=4.91 \times 10^{6}$, and $\mathrm{P}$, total $(\mathrm{psi})=89.36, \mathrm{AoA}=0$ degrees, 500 psia engine chamber pressure. 


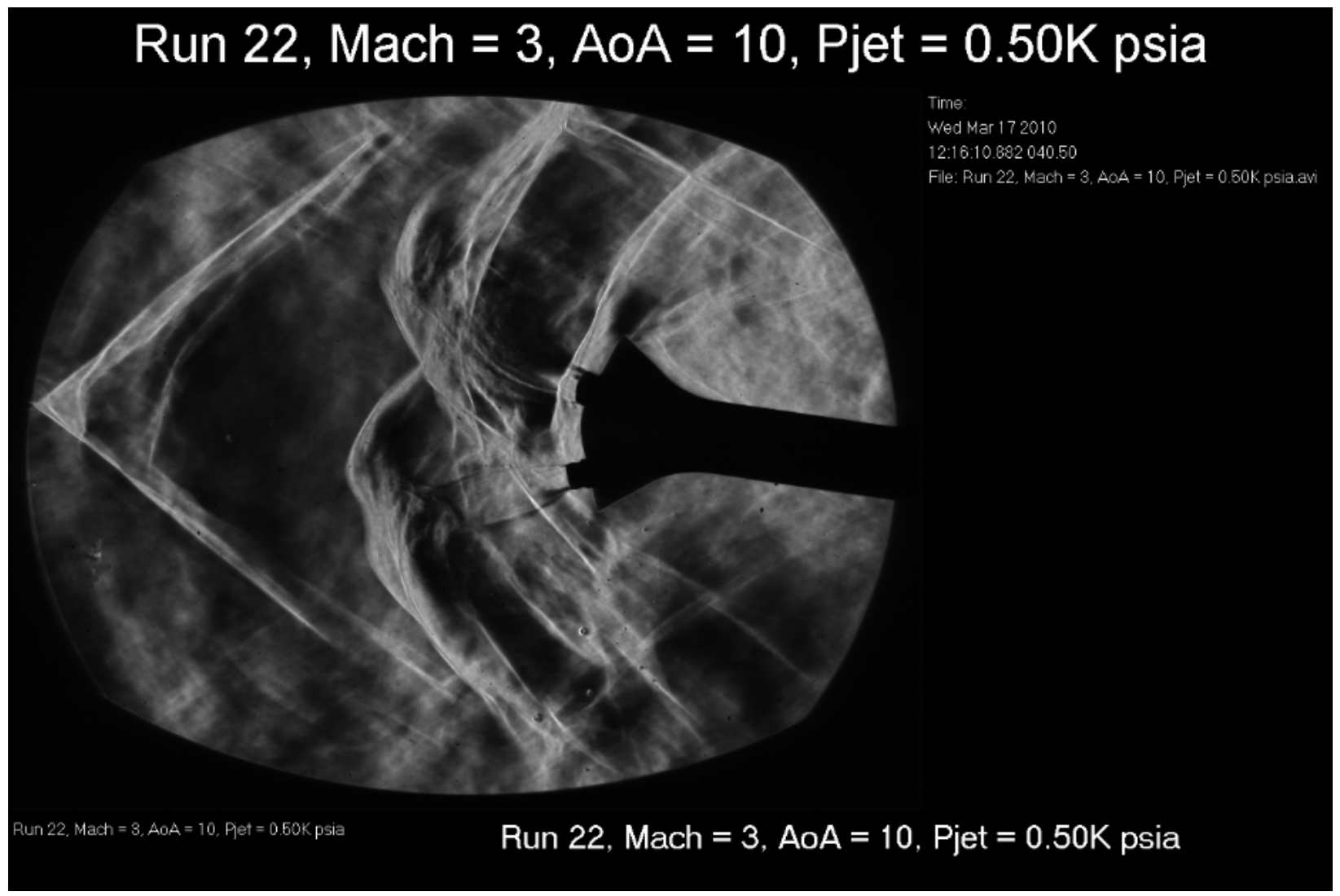

Figure A3-1. Schlieren image from 1x1 SWT testing - three engine model, Mach $=3.0, \mathrm{Re} / \mathrm{ft}=1.44 \times 10^{6}$, and $\mathrm{P}$, total $(\mathrm{psi})=8.66, \mathrm{AoA}=10$ degrees, 500 psia engine chamber pressure, tunnel unstart.

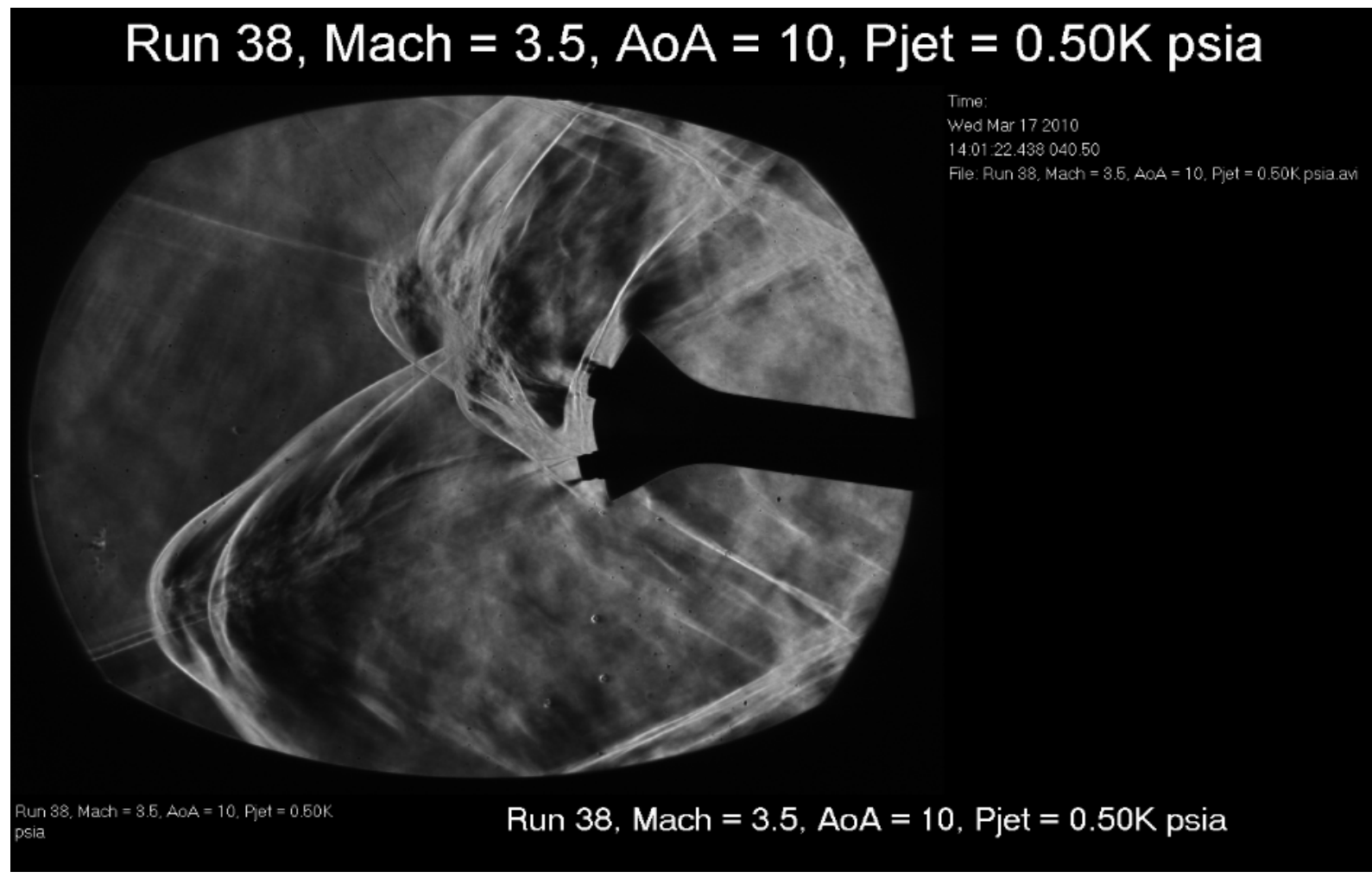

Figure A3-2. Schlieren image from 1x1 SWT testing - three engine model, Mach $=3.5, \mathrm{Re} / \mathrm{ft}=1.86 \times 10^{6}$, and $\mathrm{P}$, total $(\mathrm{psi})=15.00, \mathrm{AoA}=10$ degrees, 500 psia engine chamber pressure. 
Appendix A3: AoA = 10 degrees, 500 psia chamber pressure (continued).

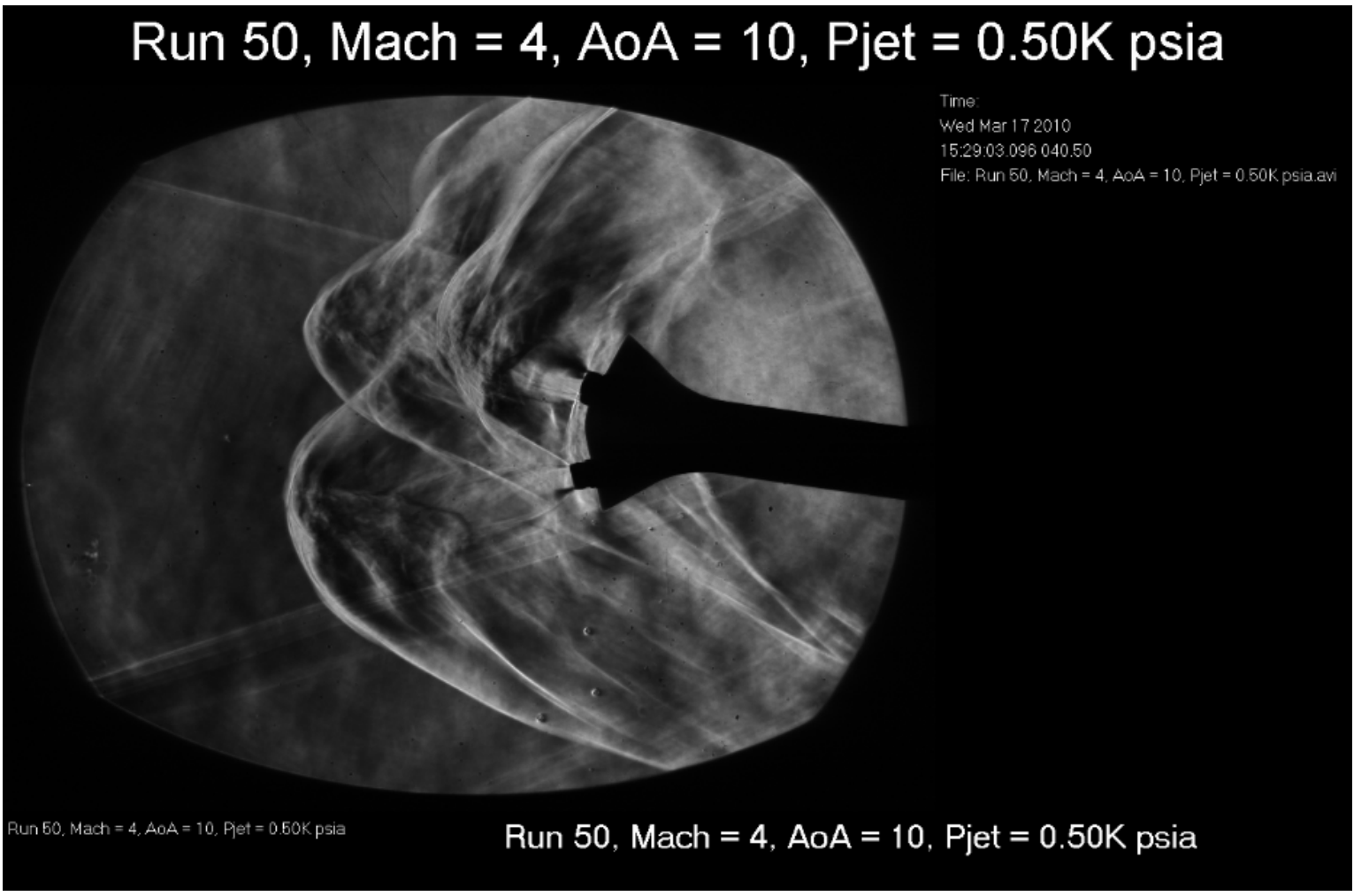

Figure A3-3. Schlieren image from 1x1 SWT testing - three engine model, Mach $=4.0, \mathrm{Re} / \mathrm{ft}=2.56 \times 10^{6}$, and $\mathrm{P}$, total $(\mathrm{psi})=26.01, \mathrm{AoA}=10$ degrees, 500 psia engine chamber pressure.

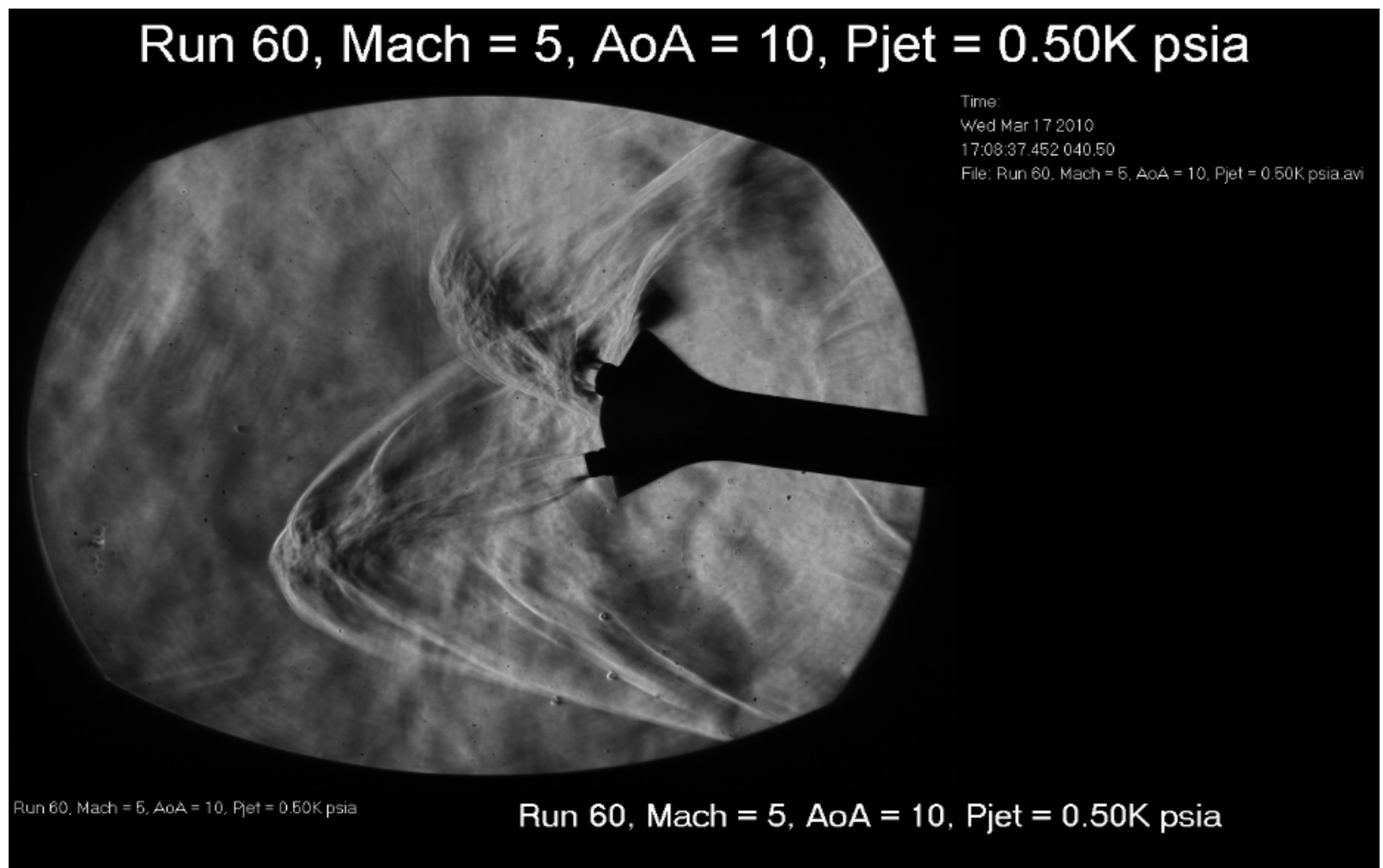

Figure A3-4. Schlieren image from 1x1 SWT testing - three engine model, Mach $=5.0, \mathrm{Re} / \mathrm{ft}=5.42 \times 10^{6}$, and $\mathrm{P}$, total $(\mathrm{psi})=90.40, \mathrm{AoA}=10$ degrees, 500 psia engine chamber pressure. 
Appendix B: SRP Run data, 1x1 SWT

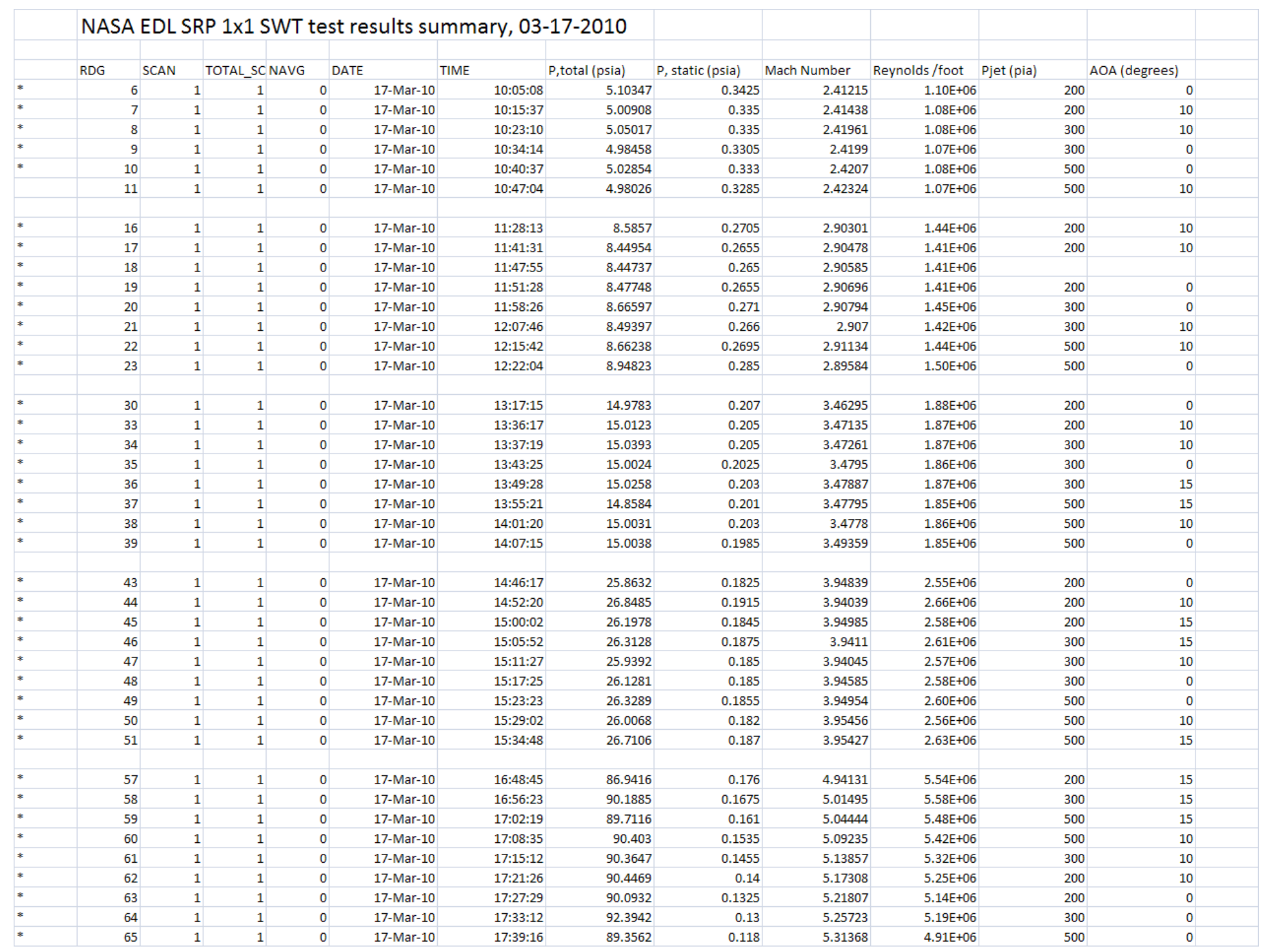


Appendix C: Model drawing, front (windward) of the aeroshell

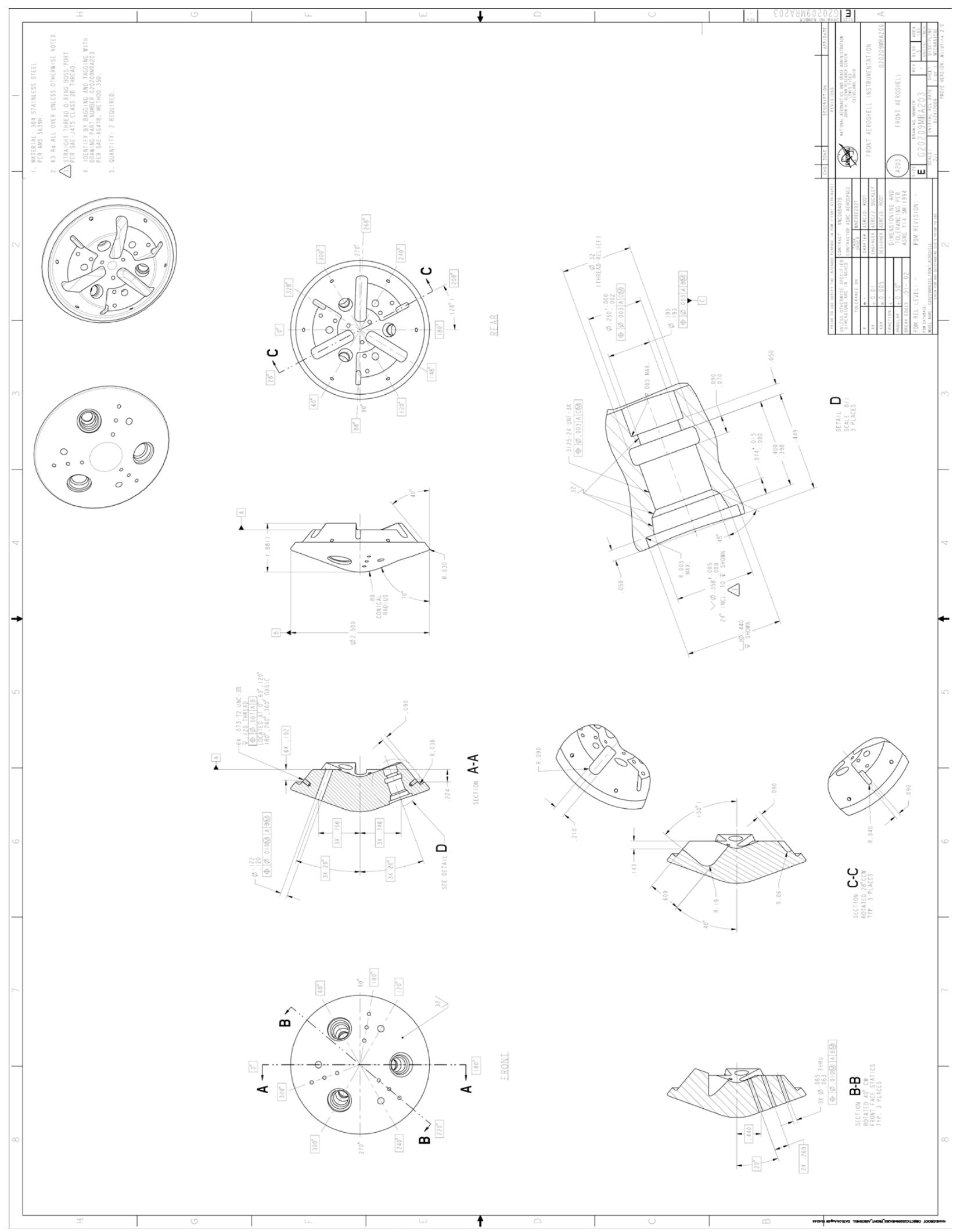

